\title{
马钱子碱的结构修饰和手性应用
}

\author{
董子阳杨占会* 许家喜 \\ (北京化工大学化学学院有机化学系 北京 100029)
}

\begin{abstract}
摘要 从结构修饰与手性应用的角度, 综述了关于马钱子碱的最新研究进展. 马钱子碱具有多个官能团和复杂的立体 结构, 对其进行选择性结构修饰极具挑战性. 目前已有多种方法实现了在其特定位点的选择性反应，具体包括：芳环 部分的脱甲氧基五氟苯基化, 酰胺部分的伯胺缩合、脱氧氰基化、脱氧还原、 $\alpha$-肜化等反应，叔胺部分的 $N$-氧化、 $\mathrm{C}$ $\mathrm{N}$ 或 $\alpha-\mathrm{C}-\mathrm{H}$ 键的形式上卡宾插入、与苯炔和酚的三组分反应、与乃春的 $N$-胺负离子化和与卤代烃的 $N$-烃基化等反应, $\mathrm{C}=\mathrm{C}$ 双键的双差基化和氢化反应，醚键的氢化断裂反应. 其修饰后的结构具有独特的生物活性和潜在的药用价值. 马 钱子碱本身可作为手性拆分试剂, 对外消旋的羧酸、磷(膦)酸、酚、醇和药物进行拆分. 此外, 马钱子碱及其结构修饰 产物均可作为手性助剂、手性催化剂或手性配体运用到不对称合成中.
\end{abstract}

关键词 马钱子碱; 结构修饰; 手性拆分; 不对称合成

\section{Structural Modifications and Chiral Applications of Brucine}

\author{
Dong, Ziyang Yang, Zhanhui* Xu, Jiaxi \\ (Department of Organic Chemistry, College of Chemistry, Beijing University of Chemical Technology, Beijing 100029)
}

\begin{abstract}
The recent advances on the structural modifications and chiral applications of Brucine are reviewed. Brucine is a naturally occuring molecule with multiple functional groups and a complex stereochemical structure. Selective structural modification of brucine is challenging, and a variety of methods to achieve selective modifications at its specific site are available. The aryl moiety undergoes demethoxypentafluorophenylation, and the amide moiety undergoes the condensation with primary amine, deoxycyanation, deoxygenative reduction, and $\alpha$-oximation. The tertiary amine moiety undergoes $N$-oxidation, formal carbene insertions of $\mathrm{C}-\mathrm{N}$ or $\alpha-\mathrm{C}-\mathrm{H}$ bonds, three-component reactions with benzynes and phenols, $N$-amidation with nitrene, and $N$-alkylation with halogenated hydrocarbons. The $\mathrm{C}=\mathrm{C}$ subunit undergoes dihydroxylation and hydrogenation, while the ether subunit undergoes hydrogenative cleavage. The modified structures have high potential medicinal values. As a chiral resolution reagent, brucine has been widely used in the resolution of racemic carboxylic acids, phosphoric or phosphonic acids, phenols, alcohols and some drugs. Additionally, brucine and its modified structures also find applications as chiral auxiliaries, chiral catalysts or chiral ligands in asymmetric synthesis and catalysis.
\end{abstract}

Keywords brucine; structural modification; chiral resolution; asymmetric synthesis

马钱子是一种传统中药, 始载于《本草纲目》, 多 种现代中药的配方中均含其成分 ${ }^{[1]}$. 普遍认为, 中国古 代毒药 “牵机药” 即未经炮制的马钱子. 马钱子的主要 活性成分是马钱子碱(1, Brucine)和番木鳖碱(2, 又名士 的宁, Strychnine $)^{[2]}$. 1819 年, 法国化学家 Pelletier 和 Caventou 在马钱子树皮中发现了马钱子碱 ${ }^{[3]}$. 直到 1884 年, 化学家 Hanssen 才通过实验, 将马钱子碱和士的宁 转化为相同的分子, 确定了马钱子碱与番木鳖碱拥有非 常相似的结构 ${ }^{[4]}$. 将马钱子碱苯环上 10 和 11 两个位置
的甲氧基换为氢原子, 就是番木鳖碱(图 1$)^{[5]}$. 虽然马钱 子碱的毒性比番木鳖碱弱, 但成人摄入 $2 \mathrm{mg}$ 纯马钱子 碱, 也会表现出类似于番木鳖碱中毒的症状 ${ }^{[6]}$. 有研究 表明, 甘草等中药有缓解马钱子碱中毒症状的作用 ${ }^{[7]}$. 此外，马钱子碱还是目前最苦的生物碱. 当饮水中马钱 子碱的含量为 $7 \mathrm{mg} / \mathrm{L}$ 时, 便可明显感觉到苦味 ${ }^{[8]}$.

马钱子碱具有抗炎镇痛、抑制肿瘤血管生成等作 用 ${ }^{[9]}$, 但其高肾毒性、神经中枢毒性、低水溶性以及较 窄的治疗窗口限制了该生物碱在医药领域的应用 ${ }^{[10]}$.

* Corresponding author. E-mail: zhyang@mail.buct.edu.cn

Received April 29, 2020; revised June 17, 2020; published online July 8, 2020.

Project supported by the Beijing Natural Science Foundation (No. 2202041) and the National Natural Science Foundation of China (No. 21602010). 北京市自然科学基金(No. 2202041)和国家自然科学基金(No. 21602010)资助项目. 

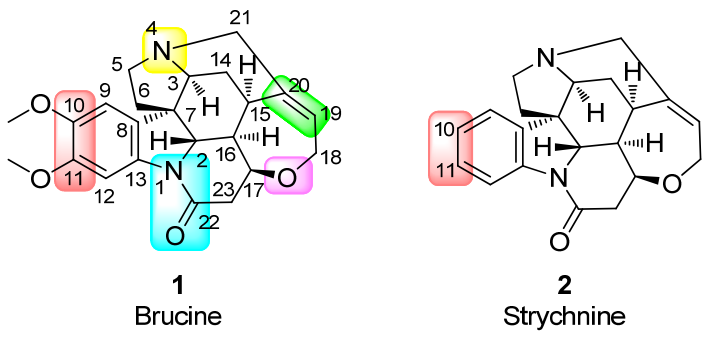

图 1 马钱子碱与番木鳖碱结构式

Figure 1 Structures of brucine and strychnine

使用传统炮制的方法可以将少部分马钱子碱(1)转化成 相应的 $N$-氧化物 3 (Scheme 1), 后者在保留生物活性的 同时毒性大幅度削弱, 拓宽了马钱子的治疗窗口并增强 了药用安全性 ${ }^{[1]]}$. 但不同产地以及不同方法炮制的马钱 子中生物碱的含量差异较大, 仍需使用高效液相色谱等 现代分析仪器准确检测其含量 ${ }^{[12]}$. 因为马钱子碱具有 刺激中枢神经的效果，也曾作为兴奋剂被不正当地运用 在体育运动领域 ${ }^{[13]}$.

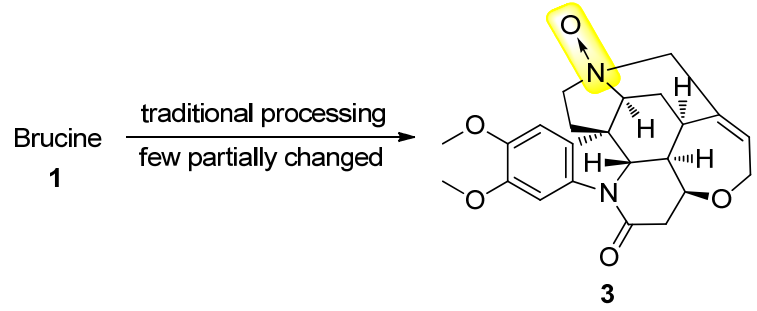

图式 1 马钱子中药炮制过程中的反应

Scheme 1 Reaction involved in the traditional processing of Strychnos nux-vomica L.

尽管马钱子碱在医药领域受到诸多限制，但其在有 机化学领域却流光异彩. 对其丰富的官能团研究促进了 其化学合成方法学的发展; 对其结构进行修饰得到诸多 具有潜在药用价值的马钱子碱衍生物, 并对其他药物后 期修饰提供了可借鉴的方法; 作为天然的手性碱可以运 用到手性拆分和不对称合成中. 本文将从马钱子碱各个 反应位点的结构修饰, 以及其本身和其衍生物作为手性 拆分剂、手性催化剂、手性配体和手性助剂的实际应用 两个角度进行分类综述.

\section{1 马钱子碱的结构修饰}

马钱子碱具有 6 个手性中心, 一个芳香环, 一个酰 胺官能团, 一个单独的叔胺位点, 一个 $\mathrm{C}=\mathrm{C}$ 双键和两 个烯丙型位点(图 1). 在不引入额外保护基的情况下实 现对其单一位点的后期结构修饰是合成化学的一大挑 战.

因此, 对其丰富的官能团转化研究能够极大地促进 化学合成方法学的发展. 尽管新开发出的有机合成方法
在短时间内不能促进社会生产，但这些方法的潜在应用 价值仍值得我们注意. 很多早期开发的合成方法已经广 泛应用于制药行业 ${ }^{[14]}$, 对社会的进步起到了积极的作 用. 此外, 对马钱子碱的后期结构修饰往往只需一两步 反应就能得到天然产物的类似物，相比于从头合成更高 效、快速. 这些类似物大多能够改变天然分子的部分生 物活性, 如改变与受体的结合能力、在生物体内的代谢 时间、水相或油相中的溶解度等. 生物活性的改变有可 能会大幅提升天然分子的药用价值 ${ }^{[15]}$. 如上文所述, 将 马钱子碱转化为相应的 $N$-氧化物后, 药用价值会有极 大的提升 ${ }^{[11]}$.

本节将综述马钱子碱的结构修饰及部分衍生物的 重要应用价值.

\section{1 芳香环参与的反应}

由于马钱子碱反应活性位点丰富, 选择性对苯环结 构单元修饰较为困难. 虽然有较多关于番木鳖碱的苯环 衍生化的报道 ${ }^{[16]}$, 但直接对马钱子碱苯环的修饰却非 常少. 2016年, König 课题组 ${ }^{[17]}$ 以曙红 Y (Eosin Y) 为光催 化剂, 三乙胺作为电子给体, 在波长为 $535 \mathrm{~nm}$ 的绿光照 射下，实现了对马钱子碱芳环上 11 号位点上的脱甲氧 基多氟芳基化(Scheme 2). 在光催化体系的介导下，五 氟溴苯(4)的 $\mathrm{C}_{\mathrm{Ar}}-\mathrm{Br}$ 键均裂生成五氟苯基自由基 $\left(\mathrm{C}_{6} \mathrm{~F}_{5} \bullet\right)$, 之后与马钱子碱反应，以 $71 \%$ 的收率获得了对 11 号位甲氧基选择性取代的产物 5.

该反应实现了温和条件下对马钱子碱的区域选择 性反应，并且前期不需要官能团保护. 因此，该实验方 法在天然分子后期功能化方面具有较大的发展潜力. 由 于包括五氟苯基在内的多氟芳基也是重要的药物活性 结构基元 ${ }^{[18]}$, 故经过五氟苯基修饰的马钱子碱衍生物 也很可能具有潜在的药用价值. 尽管该官能团的引入会 大幅度改变马钱子碱芳环的电性，但对叔胺、酰胺、 $\mathrm{C}=\mathrm{C}$ 双键等官能团影响较小. 此外, 五氟苯基也是具 有一定化学活性的官能团, 可以在多种条件下实现脱氟 官能团化 ${ }^{[19]}$, 为未来进一步研究马钱子碱衍生物的生 物活性和手性应用做出了铺垫.

\section{2 酰胺部分参与的反应}

马钱子碱酰胺部分能发生缩合偶联和还原反应. 由 于其空间结构较为复杂, 酰胺官能团的岸基部分裸露在 外. 羰基氧的亲核性及其碳的亲电性是该位点能够发生 化学反应的内因. 此外受酰胺官能团的影响, 其 $\alpha-\mathrm{H}$ 具 有一定的酸性，也可以发生一系列反应.

\subsection{1 酰胺与伯胺的缩合}

2013 年, Figueroa-Valverde 课题组 ${ }^{[20]}$ 以硼酸为催化 剂, 用马钱子碱与含伯胺官能团化合物 6 (图 2)缩合偶 


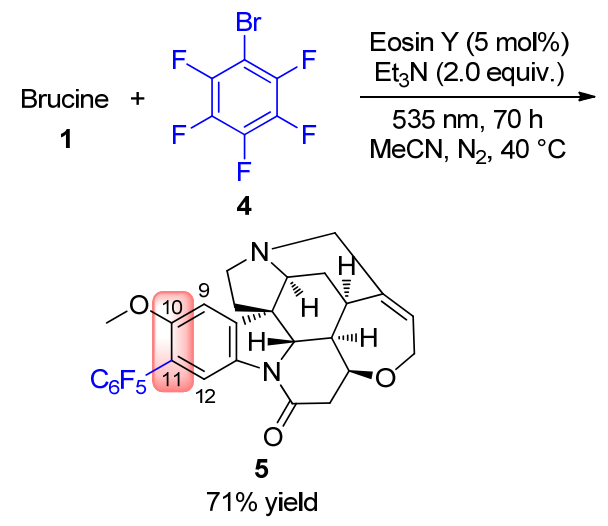

图式 2 马钱子碱芳香环上的光氧化还原反应

Scheme 2 Photoredox reaction on the aromatic ring of brucine
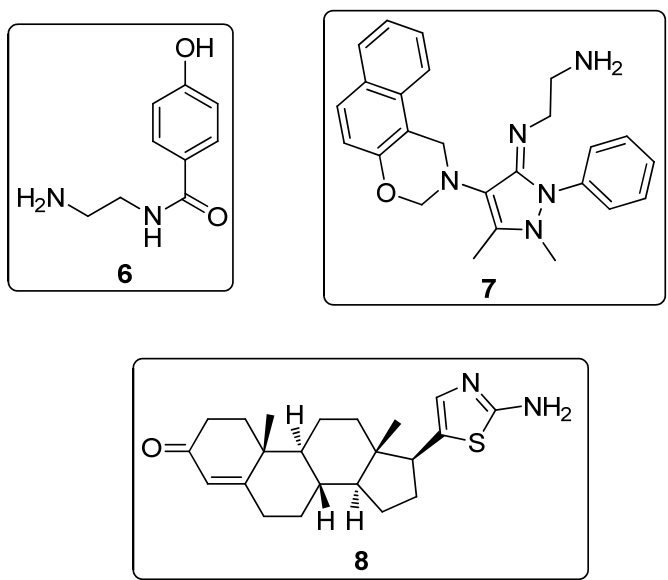

图 2 Figueroa-Valverde 课题组使用的含伯胺官能团的化合物

Figure 2 Primary amine-containing compounds used by Figueroa-Valverde's group

联, 以 $62 \%$ 的收率得到了相应的榺类化合物 9 (Scheme $3 a$ ). 次年, 该课题组利用相同的方法, 实现了马钱

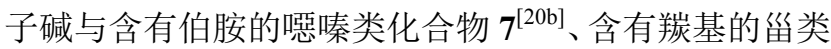
化合物 $\mathbf{8}^{[20 \mathrm{c}]}$ 的组装反应(Schemes $\left.3 b, 3 c\right)$.

该实验方法条件温和简单，无需昂贵的催化剂，反 应收率普遍中等偏上，实用价值较高. 通过该方法可以 高效地将两种复杂分子偶联在一起, 官能团容忍性强. 该方案获得的马钱子碱衍生物的药用价值还有待进一 步探究.

\subsection{2 酰胺的还原}

马钱子碱双键和酰胺部分均可发生还原反应, 若使 用氢化铝锂、硼氢化钠等常见的强还原剂难以实现酰胺 部分的选择性还原. 使用适当的亲电试剂将羰基活化, 可促进选择性还原反应. 具有亲电性和亲氧性的硅烷类 化合物是理想的活化试剂之一.

2017 年, Dixon 课题组 ${ }^{[21]}$ 以四甲基二硅氧烷(12, TMDS)为还原剂, 实现了铱催化的酰胺部分选择性硅 氢化; 硅氢化产物 14 通过亚胺正离子中间体 15, 进一 步发生 Strecker 型反应，以 55\%的中等产率得到了氰基 化产物 13 (Scheme 4). 由于氰基具有线性、大极性、可 与含活泼氢物质形成氢键等性质，故被氰基修饰的有机 物也往往具有重要的药物活性 ${ }^{[22]}$. 除了潜在的药用价 值外, 由于氰基也是重要的活性官能团 ${ }^{[23]}$ ，也可以在 13 的氰基位点上进一步结构修饰.

同年, Gagné 课题组 ${ }^{[24]}$ 用特定的有机硼试剂 16 作为 Lewis 酸活化硅烷上的 $\mathrm{Si}-\mathrm{H}$ 键, 得到了超亲电性 (super-electrophilic)的硅正离子, 很好地和酰胺氧原子 络合 (活化酰胺), 最终, 将酰胺部分还原成了胺 17 (Scheme 5). 该方法反应条件温和，区域选择性强，对 其它天然产物后期结构修饰有高价值的借鉴意义.

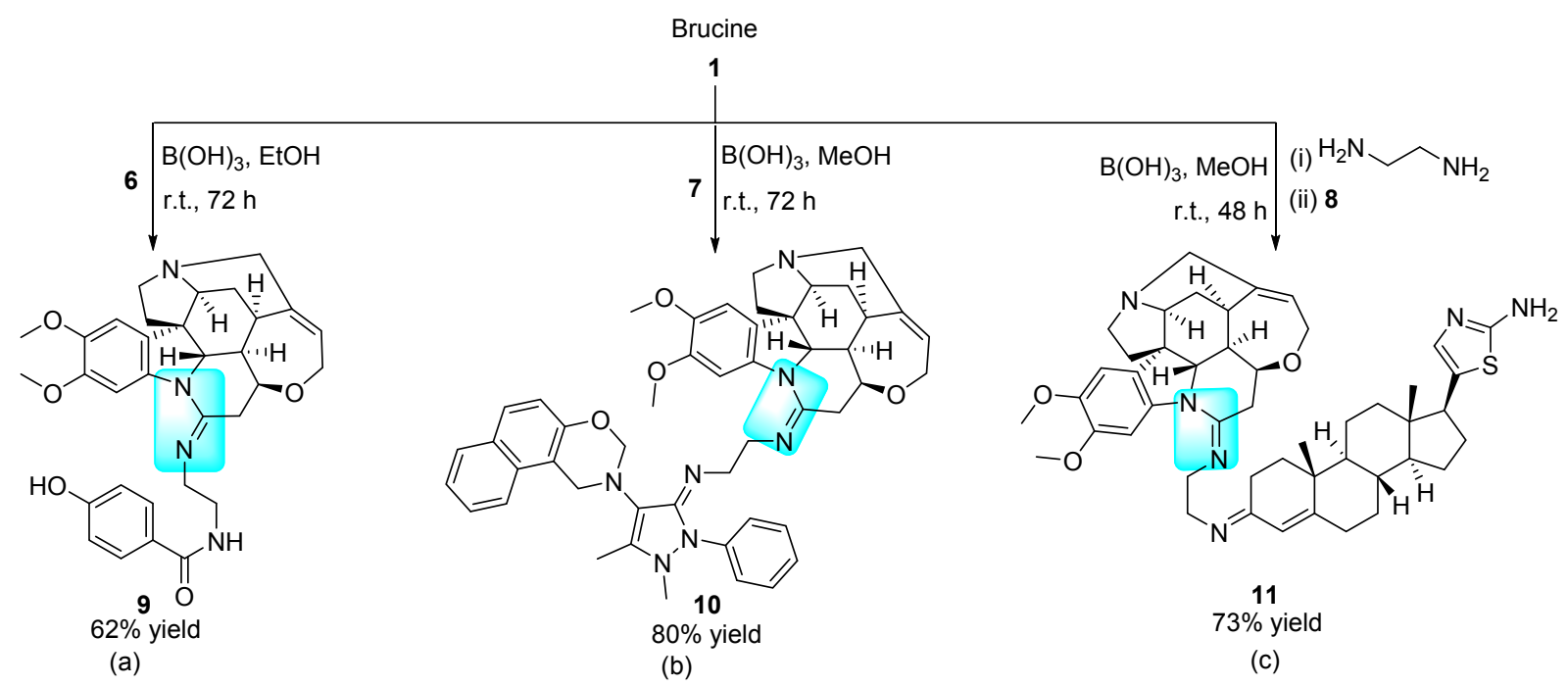

图式 3 酰胺与伯胺转化成榺

Scheme 3 Conversion of amide with primary amine into amidines 


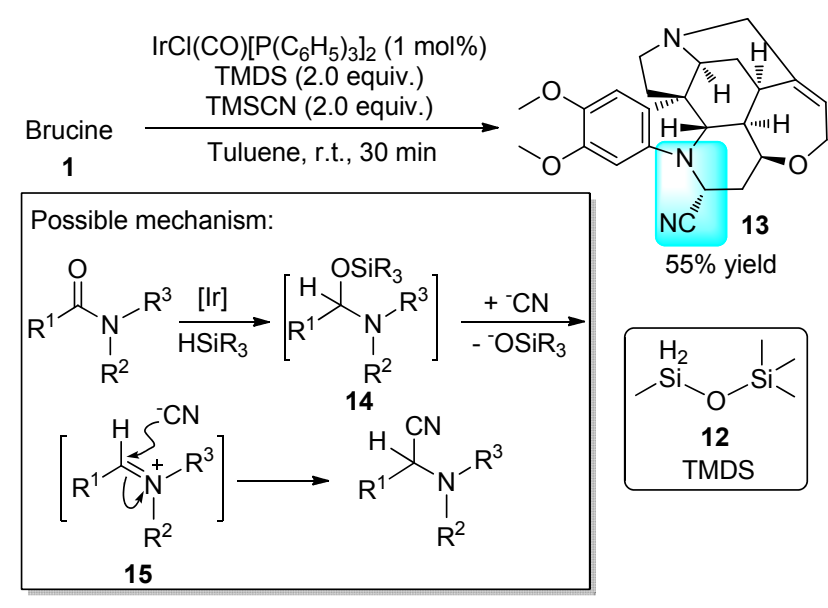

图式 4 铱催化的选择性氢氰基化反应

Scheme 4 Iridium-catalyzed selective hydrocyanation reaction

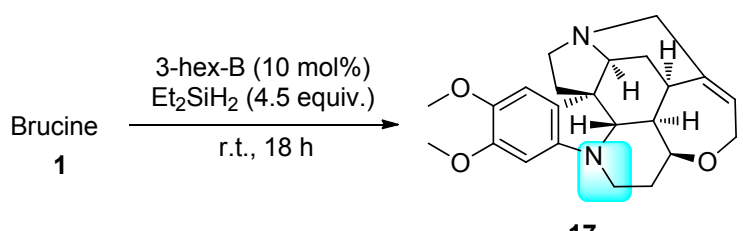

17

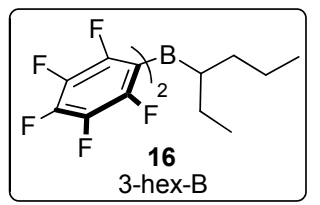

Possible mechanism:

图式 5 有机嗍催化的酰胺选择性还原

Scheme 5 Organic borane-catalyzed selective reduction of amide

\subsection{3 氧化酰胺 $\alpha$-位成肜}

2003 年 Zlotos 课题组 ${ }^{[25]}$ 用叔丁醇钾对马钱子碱酰 胺 $\alpha$-位去质子化, 再对叔丁基亚硝酸酯(21)亲核取代, 得到了相应的亚硝基化合物，经互变异构，最终以 $89 \%$ 的产率得到了带有肜官能团的马钱子碱衍生物 22 (Scheme 6). 将 22 进一步衍生化可得到潜在的药用分子 (详见第 1.3 .5 节).

\section{3 叔胺部分参与的反应}

马钱子碱的叔胺部分富有电子, 具有一定的还原 性、碱性和亲核性. 因此, 这部分可以发生氧化、亲核

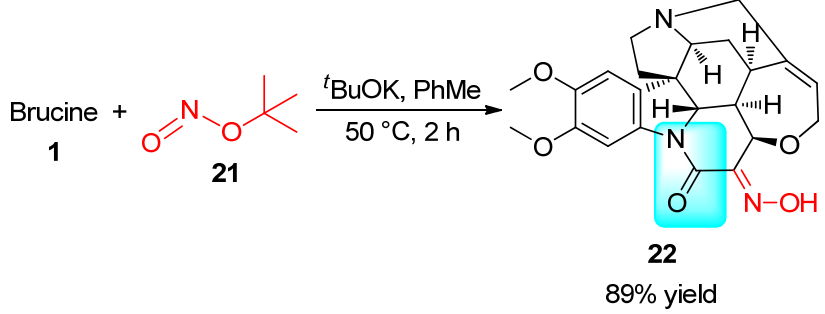

图式 6 酰胺 $\alpha$ 位的肜化反应

Scheme 6 Oximation of the $\alpha$-methylene of amide

取代等多种化学反应. 此外, 氮原子有三个 $\alpha-\mathrm{C}$, 选择 性 $\alpha-\mathrm{C}-\mathrm{H}$ 键官能团化也受到许多化学方法学研究者的 青睐.

\subsection{1 叔胺被氧化成 $N$-氧化物及后续还原}

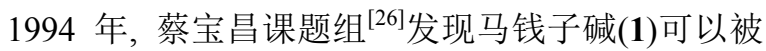
过氧化氢氧化成相应的 $N$-氧化物 $\mathbf{3}$, 该反应产率可达 95\% (Scheme 7). 1998 年, Resnati 课题组 ${ }^{[27]}$ 实现了用全 氟代的氧杂听丙啶试剂 23 对马钱子叔胺部分的氧化, 以 $97 \%$ 的收率获得了马钱子碱 $N$-氧化物(3) (Scheme 7). $N$-氧化物 3 的重要药用价值在前文中已有描述 ${ }^{[11]}$.

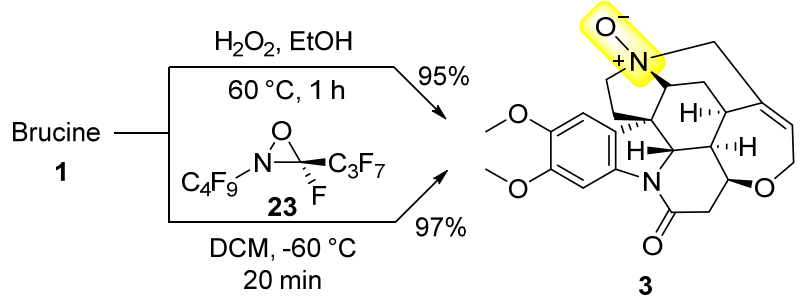

图式 7 马钱子碱被氧化成氮氧化物

Scheme 7 Oxidation of brucine to its $N$-oxide

马钱子碱的 $N$-氧化物可以被多种还原剂还原. 1987 年, Jousseaume 课题组 ${ }^{[28]}$ 用六正丁基二锡将马钱子碱 $N$ 氧化物 (3) 还原成了马钱子碱，该反应产率为 $84 \%$ (Scheme 8a). 同年, 周洵钧课题组 ${ }^{[29]}$ 以碲氢化钠作为温 和的还原剂, 在弱酸性条件下以 $84 \%$ 的收率实现了对 3 的选择性还原(Scheme 8b). 1994 年, 蔡宝昌课题组 ${ }^{[26]}$ 研 究马钱子碱被过氧化氢氧化的过程中, 发现了其 $N$-氧 化物(3)可以被亚硫酸氢钠还原(Scheme 8c). 2009 年, Oh 课题组 ${ }^{[30]}$ 使用蔡宝昌课题组发展的氧化条件, 获得了 马钱子碱 $N$-氧化物(3). 随后, 以五氯化铌为催化剂, 锌 为还原剂, 以 $95 \%$ 的产率实现了对 3 的还原 (Scheme $8 \mathrm{~d}$ ). 以上还原中, 亚硫酸氢钠还原法廉价、安全、便捷、绿 色，不失为一种优秀的还原反应.

1.3.2 叔胺相邻位点的 $\mathrm{C}-\mathrm{N}$ 键或 $\mathrm{C}-\mathrm{H}$ 键插入反应 2012 年, Davies 课题组 ${ }^{[31]}$ 在无过渡金属催化情况下 实现了卡宾对马钱子碱的形式 $\mathrm{C}-\mathrm{N}$ 键插入反应. 在该 反应中, 首先富电子的叔胺对游离卡宾 24 进行亲核进 攻得到氮叶立德中间体 25. 随后发生 Stevens 重排, 在 


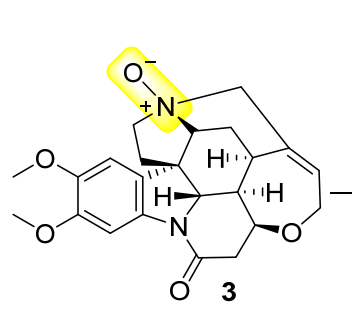

?: no clearly indicated yield
$\left(n-\mathrm{C}_{4} \mathrm{H}_{9}\right)_{6} \mathrm{Sn}_{2}$, THF

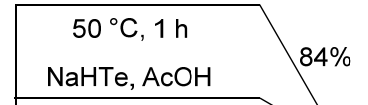

$0^{\circ} \mathrm{C}, 30 \mathrm{~min}$; r.t., $1 \mathrm{~h}$

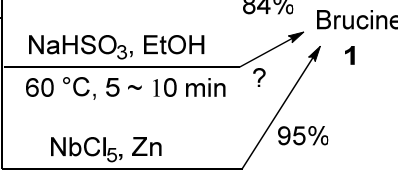

THF, $\mathrm{PhH}$

$23^{\circ} \mathrm{C}, 24 \mathrm{~h}$

图式 8 马钱子碱 $N$-氧化物的还原

Scheme 8 Reduction of brucine $N$-oxide

活性更高的烯丙型位点生成形式上 $\mathrm{C}-\mathrm{N}$ 键插入产物 26 (Scheme 9).
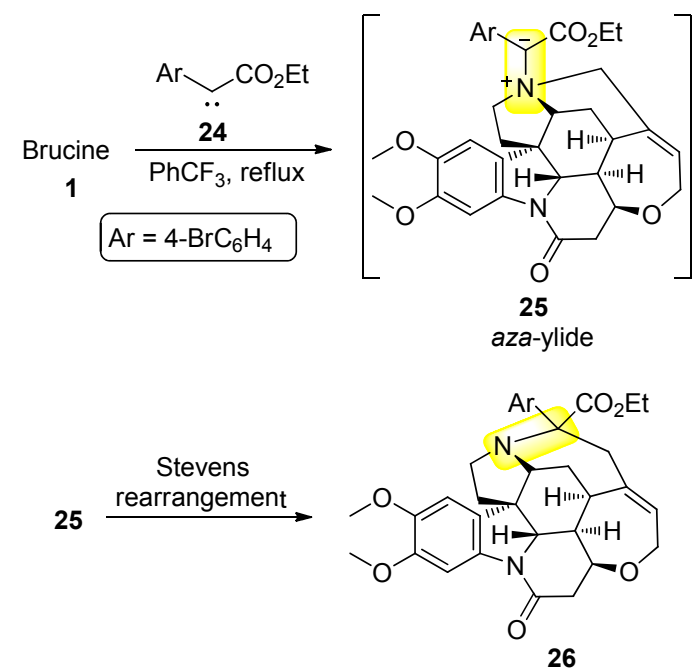

$47 \%$ yield

图式 9 马钱子碱和游离卡宾的反应

Scheme 9 Reaction of brucine with free carbene

2015 年, Beckwith 课题组 ${ }^{[32]}$ 以不同配体的铑(II)为
催化剂，用卡宾前体重氮化合物 27 和马钱子碱反应，选 择性实现了氮原子 $\alpha-\mathrm{C}-\mathrm{H}$ 键官能团化，高效地制备了 三种马钱子碱衍生物：一种和 Davies 等的研究相似，是 形成氮叶立德中间体之后再发生 Stevens 重排的产物 26 (Schemes 10a, 10b), 另外两种是直接对氮原子的 $\alpha-\mathrm{C}-$ $\mathrm{H}$ 键直接插入的产物 28 和 29 (Schemes 10b, 10c). 反应 选择性受 $\mathrm{Rh}$ 催化剂配体的控制.

2019 年, Mancheño 课题组 ${ }^{[33]}$ 以 $\mathrm{Cu}(\mathrm{II})$ 为催化剂, 用 有机过氧化物逐步将叔胺选择性地氧化成了亚胺正离 子中间体 30. 随后，亚胺正离子、异腈、羧酸负离子发 生三组分反应得到对应的 $O$-酰基亚胺酸酯中间体 31 ; 进一步发生 Mumm 重排, 得到了选择性官能团化的马 钱子碱衍生物 32 , 反应位点为被氮原子活化的烯丙位 (Scheme 11).

以上 $\mathrm{C}-\mathrm{N}$ 键或 $\mathrm{C}-\mathrm{H}$ 键插入反应，均实现了在不 改变原有重要官能团的基础上引入新的官能团. 除了得 到更多生物活性可能改变的马钱子碱衍生物外, 更重要 的意义在于扩展了对天然产物非活泼位点衍生化的方 法, 有助于提高基于天然产物结构修饰的药物开发效 率. 未来也可以将引入官能团进一步设计, 以作为生物 探针深入研究药物作用机制 ${ }^{[32]}$.

\subsection{3 叔胺与原位形成苯炔中间体的反应}

2017 年, Hoye 课题组 ${ }^{[34]}$ 使用含有三个(或更多) $\mathrm{C} \equiv$ $\mathrm{C}$ 参键的底物 33, 在加热条件下实现了分子内去六氢 Diels-Alder 反应, 得到了相应的苯炔中间体 34 (Scheme 12).

随后利用叔胺氮原子的亲核性与苯炔中间体 34 反 应, 得到了中间体 35. 经过分子内的氢转移得到氮叶立 德中间体 36. 该中间体的 20 号位点带有负电荷, 夺取 酚着基上的氢. 随后，酚氧负离子与中间体 36 的 5 号位

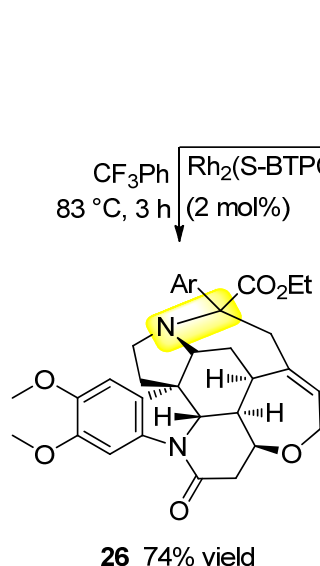

(a)

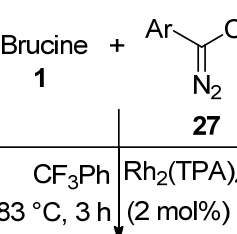

$\mathrm{Ar}=4-\mathrm{BrC}_{6} \mathrm{H}_{4}$

A) 4

$83^{\circ} \mathrm{C}, 3 \mathrm{~h} \downarrow(2 \mathrm{~mol} \%)$

$\mathrm{Rh}_{2}(\mathrm{Oct})_{4}$

$83^{\circ} \mathrm{C}, 3 \mathrm{~h} /(2 \mathrm{~mol} \%)$

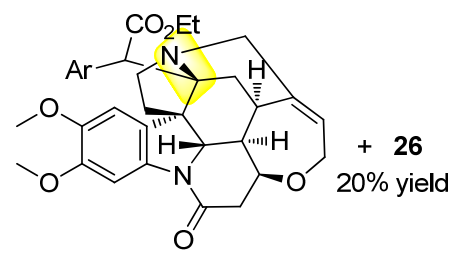

$2850 \%$ yield

(b)

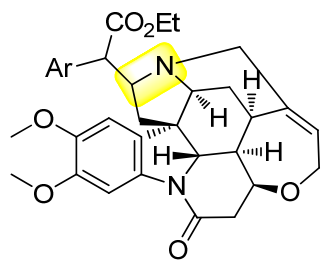

$2939 \%$ yield

(c)

图式 10 铑(II)催化下马钱子碱和重氮化合物的反应

Scheme 10 Rhodium(II)-catalyzed reactions of brucine with diazo compounds 


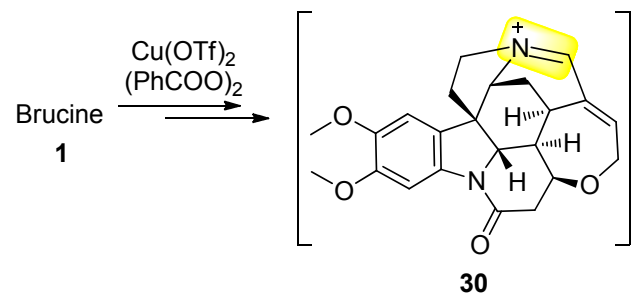

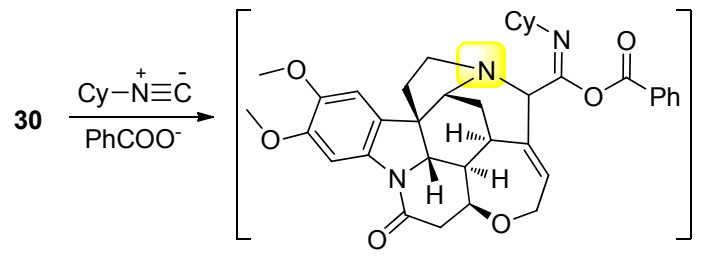

31

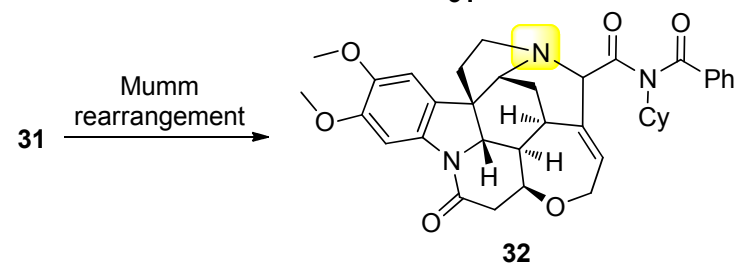

$76 \%$ yield, $78: 22 d r$

图式 11 铜(II)催化下马钱子碱和异腈的反应

Scheme 11 Copper(II)-catalyzed reaction of brucine with isonitrile

发生 $\mathrm{S}_{\mathrm{N}} 2$ 反应, 得到双键保持产物 37. 相应地, 酚氧负 离子与 22 号位通过 $\mathrm{S}_{\mathrm{N}} 2^{\prime}$ 反应得到端烯型产物 38. 氮叶 立德中间体 36 的 20 号位点与 $\mathrm{C}=\mathrm{C}$ 形成了三中心四电 子的离域体系, 使负电荷得以从 20 号位过渡到 22 号

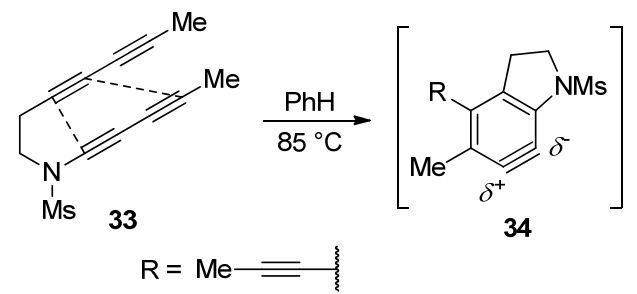

图式 12 去六氢的 Diels-Alder 反应

Scheme 12 Hexadehydro-Diels-Alder reaction

位. 22 号位夺取酚羟基上的氢之后，酚氧负离子与 5 号 位发生 $\mathrm{S}_{\mathrm{N}} 2$ 反应生成了双键迁移产物 39 (Scheme 13, 图 $3)$.

该反应能生成的产物类型和产率与酚的结构有关 (图 4). 氮叶立德中间体 36 的 20 号位电子云密度高, 但 空间位阻较大; 与之相反，22 号位电子云密度低，但空 间位阻较小. 如果使用雌二醇(40)这类酚羟基位点附近 位阻小的试剂，将会对 36 的 20 号位质子化，随后以 $55 \%$ 的中等收率得到单一的双键保持型产物 37 . 使用含 有大位阻基团的 2,6-二叔丁基对甲基苯酚(41), 将会对 36 的 22 号位质子化, 并伴随双键迁移; 随后酚氧负离 子与 5 号位发生 $\mathrm{S}_{\mathrm{N}} 2$ 反应, 得到单一的双键迁移型产物 39; 受位阻影响, 该反应收率较低, 仅为 $39 \%$. 与 40 相 比，4-甲氧基苯酚(42)分子结构更简单、空间位阻更小, 故更容易和 36 发生反应. 该反应中双键保持型产物 37 的产率提升至 $61 \%$ ，同时还得到了收率为 5\%的双键迁
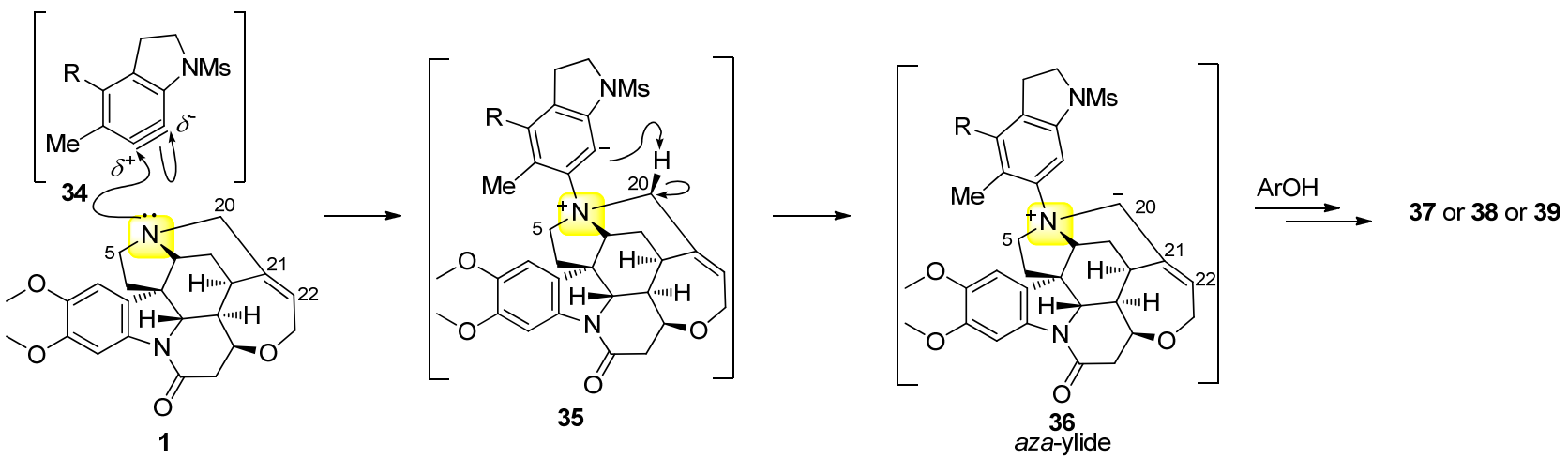

图式 13 马钱子碱与苯炔中间体的反应

Scheme 13 Reaction of brucine with benzyne intermediate

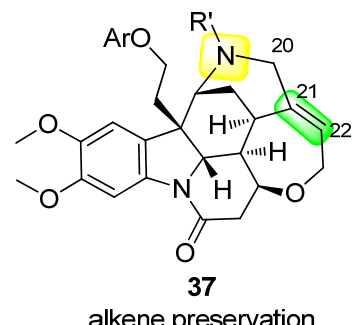

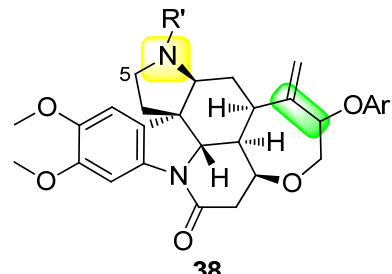

terminal alkene

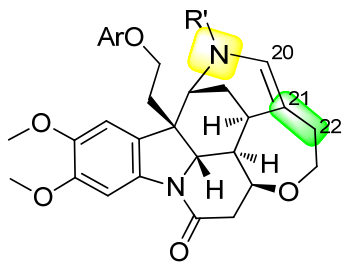

39

alkene migration

图 3 马钱子碱与苯炔中间体反应的产物结构

Figure 3 Structures of the reaction product of brucine with benzyne intermediate 


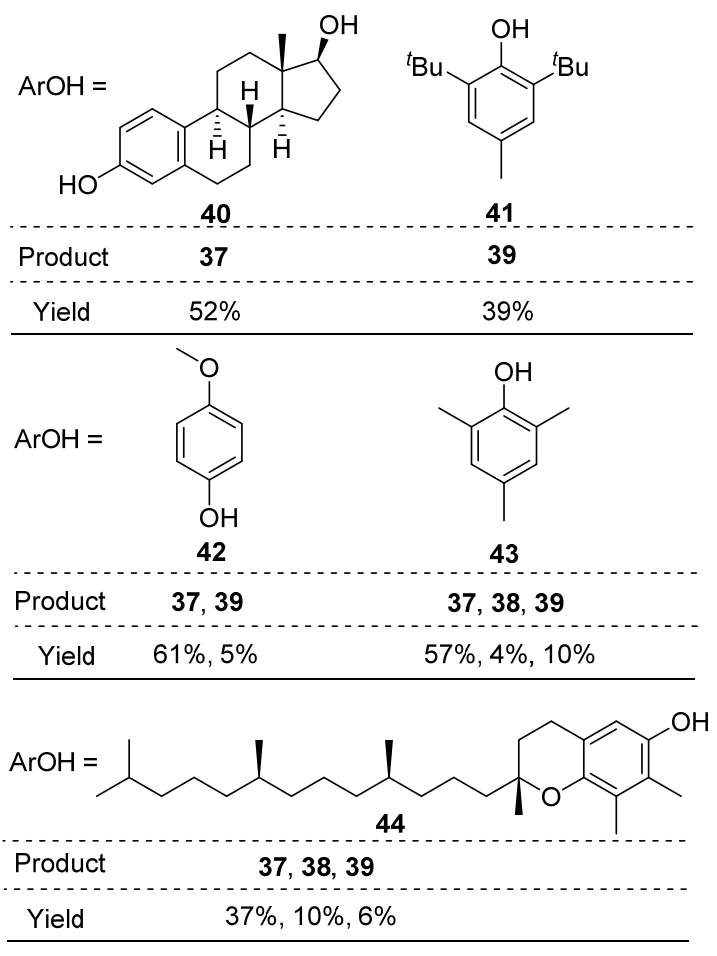

图 4 与氮叶立德中间体 36 发生反应的酚类及产物

Figure 4 Phenols applied in the reactions with aminimides intermediates 36

移型产物 39. 使用空间位阻适中的均三甲基苯酚(43)和 维生素 E (44), 除了生成 37 和 39 外, 还可以从 22 号位 点发生 $\mathrm{S}_{\mathrm{N}} 2^{\prime}$ 反应得到了端烯型产物 38 . 用 43 和 44 参与 的反应相比较, 不难发现, 随着分子复杂程度的增加, 产物的总收率有所下降. 该反应实现了三种物质的组装 反应，为天然产物的后期修饰提供了高价值的借鉴方 法.

\subsection{4 叔胺位点与金属乃春中间体的反应}

2013 年, Romo 课题组 ${ }^{[35]}$ 以双(新戊酰氧)碘苯 $(\mathbf{4 5}$, $\left.\left({ }^{t} \mathrm{BuCO}_{2}\right)_{2} \mathrm{IPh}\right)$ 为氧化剂, $\mathrm{Rh}(\mathrm{II})$ 为催化剂, 用马钱子碱和 磺酰胺 46 反应, 得到了氮-氮叶立德产物 47 . 在该反应 中 $\left({ }^{t} \mathrm{BuCO}_{2}\right)_{2} \mathrm{IPh}$ 将磺酰胺可逆地氧化成了 $\mathrm{PhI}=\mathrm{NR}$ 型亚 胺基碘烷 $49^{[36]}$. 49 与 $\mathrm{Rh}(\mathrm{II})$ 催化剂作用得到了 $[\mathrm{Rh}]=\mathrm{NR}$ 型铑乃春中间体 $\mathbf{5 0}$, 再分别与马钱子碱的叔胺氮原子 和其邻位叔碳 C- $\mathrm{H}$ 键反应, 最终得到了收率为 $28 \%$ 的 氮一氮叶立德 47 和收率为 $21 \%$ 的开环产物内酰胺 48 (Scheme 14).

值得一提的是, 含有 $\mathrm{C} \equiv \mathrm{C}$ 参键的天然分子衍生物 52 可与带标记的叠氮化物 51 反应, 生成带有标记的三 唑化合物 53. 带有标记的三唑类化合物 $\mathbf{5 3}$ 可以作为细 胞探针, 用于深入研究天然分子在生物体内的作用机制 (Scheme 15 $)^{[35]}$. 上述 37、38、39、47 等含有 $\mathrm{C} \equiv \mathrm{C}$ 参键 的马钱子衍生物都具有这种应用的潜质.

叶立德 47 在 $10 \% \mathrm{Cd} / \mathrm{Pb}^{[37]}$ 催化下，可脱除烷氧基磺

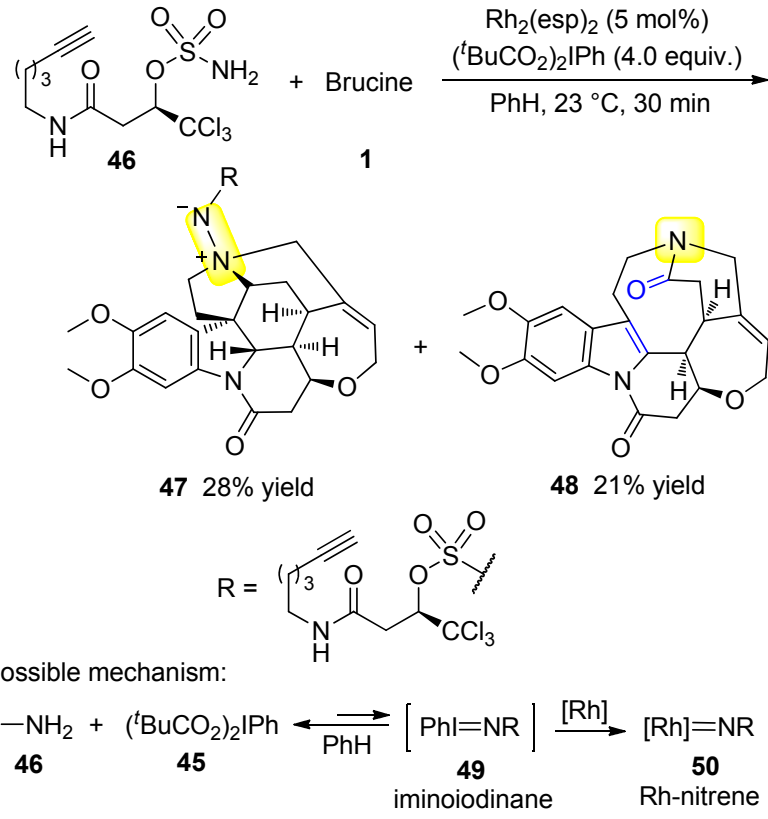

图式 14 马钱子碱与铑乃春中间体的反应

Scheme 14 Reaction of brucine with Rh-nitrene intermediate

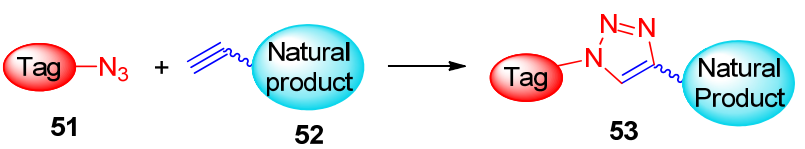

图式 15 基于天然产物的细胞探针的合成

Scheme 15 Synthesis of natural product-based cellular probes

酰基保护基 $\mathrm{R}$ 得到相应的叶立德 $\mathbf{5 4}$ ，产率可达 76\% (Scheme 16) ${ }^{[35]}$. 由于 54 正负电荷处于分离状态, 故与 马钱子碱 1 相比更易溶于水, 可大幅度改善马钱子碱 1 由于水溶性差导致的药用受限 ${ }^{[10 \mathrm{~d}]}$. 该化合物的药用价 值还有待进一步探究.

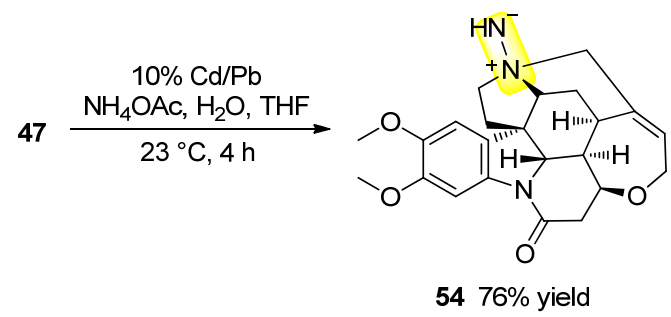

图式 $16 \quad 10 \% \mathrm{Cd} / \mathrm{Pb}$ 催化脱除烷氧基磺酰基保护基 Scheme $1610 \% \mathrm{Cd} / \mathrm{Pb}$-catalyzed removal of alkoxysulfonyl protecting groups

2017 年, Pérez 课题组 ${ }^{[38]}$ 改进了 Romo 等的方法, 以 催化性能较 $\mathrm{Rh}(\mathrm{II})$ 低的 $\mathrm{Ag}(\mathrm{I})$ 为催化剂, 在不添加氧化剂 的情况下，直接用亚胺基碘烷 $\mathrm{PhI}=\mathrm{NTs}$ 与马钱子碱反 应，以 $83 \%$ 的收率得到了唯一的叶立德产物 55 (Scheme 17). 该反应过程中也产生了与 $[R h]=N R$ 中间体相似的 $[\mathrm{Ag}]=\mathrm{NTs}$ 中间体. 与 Romo 课题组的方法相比, 该方 法反应效率更高, 无副产物生成, 实用价值更高. 


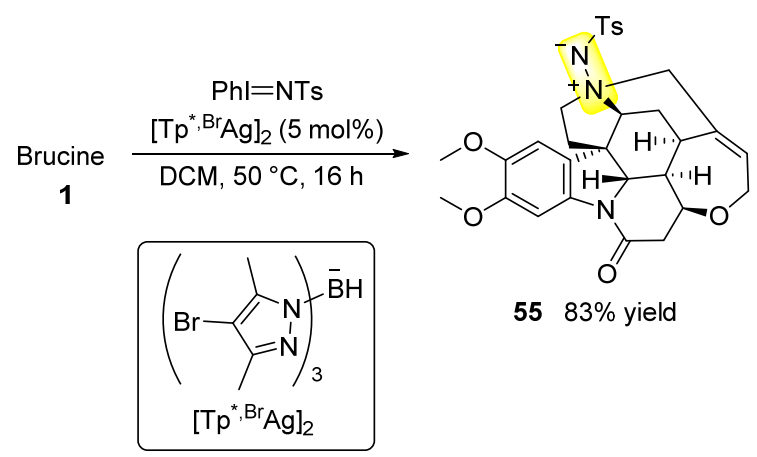

图式 17 马钱子碱与银乃春中间体的反应

Scheme 17 Reaction of brucine with Ag-nitrene intermediate

\subsection{5 叔胺位点与卤代烷烃的亲核取代反应}

叔胺氮原子亲核性较高, 可与卤代烃发生亲核取代 反应，生成多种具有实际应用价值的马钱子碱衍生物. 本文列举几处典型的应用.

1999 年, Birdsall 课题组 ${ }^{[39]}$ 用马钱子碱和几种简单 的卤代烃反应，得到了相应的季铵盐衍生物 $56 \sim 59$ (Scheme 18). 除和卤代物反应外, 还和磺酰羟胺反应得 到了叔胺位点胺化的产物 60 . 该研究证实马钱子碱季 铵盐可以作为神经递质乙酰胆碱(61)受体蛋白变构剂, 对五种毒䓥碱型受体(Muscarine 受体, 简称 M 受体, 有 M1 M5 五种亚型)都有一定的亲和力. 衍生物 $\mathbf{5 6} \sim \mathbf{6 0}$ 对 $\mathrm{M}$ 受体产生变构作用后, 都能选择性地增强乙酰胆 碱和 M3 受体的结合能力(正协同作用)(图 5), 并抑制乙 酰胆碱和其他四种亚型 $\mathrm{M}$ 受体相结合(负协同作用). 未 经衍生化的马钱子碱(1)仅在 M1 亚型受体上与乙酰胆碱 有正协同作用, 而马钱子碱氮氧化物(3)在 M3 和 M4 受 体上与乙酰胆碱均有正协同作用. 这些研究证明，马钱 子碱季铵盐衍生物具有治疗阿尔茨海默病的潜在效果.

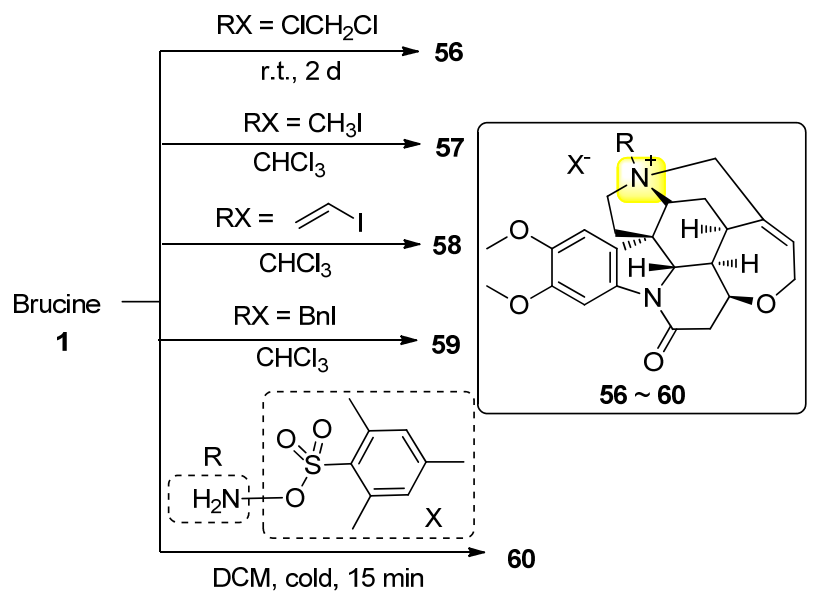

56: $80 \%$ yield; $57 \sim 59$ : in quantitative yields; 60 : $51 \%$ yield

图式 18 马钱子碱季铵衍生物的合成

Scheme 18 Synthesis of brucine quaternary ammonium derivatives

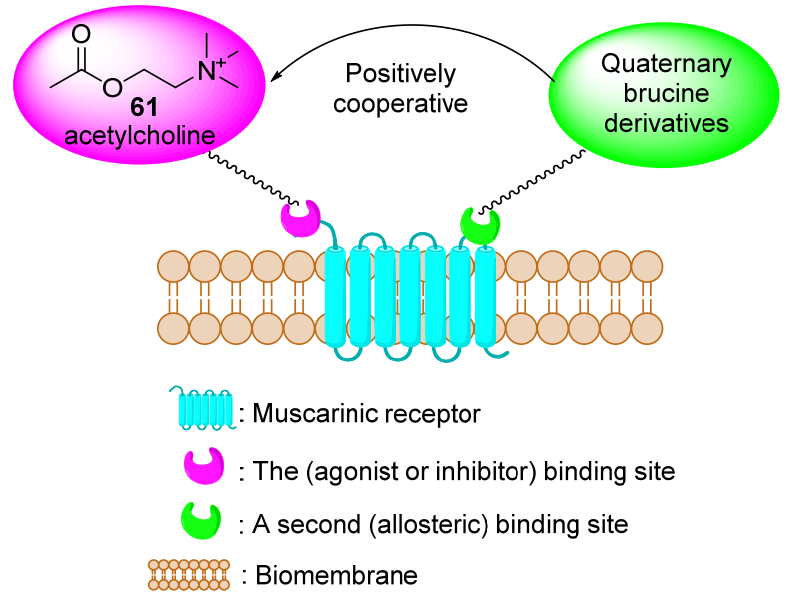

图 5 马钱子碱季铵衍生物的变构作用

Figure 5 Allosteric interactions of brucine quaternary ammonium derivatives

2003 年 Zlotos 课题组 ${ }^{[25]}$ 用端位二卤代烷将两分子 的马钱子碱相连, 得到了多个双马钱子碱季铵盐衍生物 62 (Scheme 19). 这些化合物可以作为毒草碱 M2 受体的 变构剂, 能够增加相应拮抗剂与 $\mathrm{M} 2$ 受体的亲和力. 该 方法也适用于之前所得肜类化合物 22 的偶联, 得到相 应的马钱子碱衍生物 63 (Scheme 20). 通过实验对比分 析, 带有肜官能团的 63 与猪心 M2 受体的结合能力比马 钱子碱 1 高 56 倍左右, 62 这类双马钱子碱衍生物与猪心 M2 受体的结合能力比马钱子碱 1 高 115 倍左右.

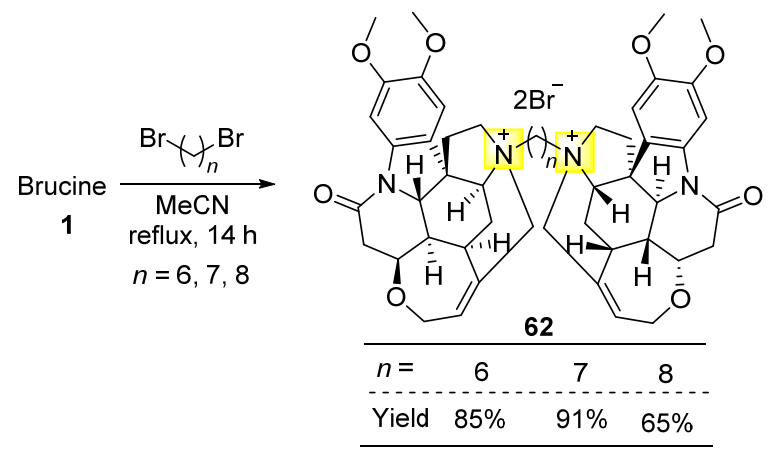

图式 19 双马钱子碱季铵盐 62 的合成

Scheme 19 Synthesis of bisquaternary ammonium dimers of brucine 62

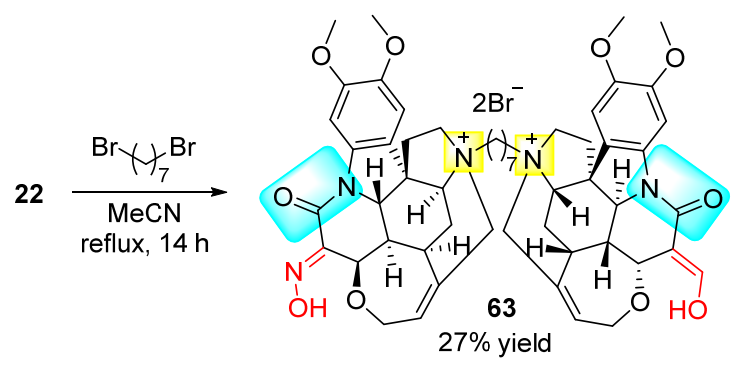

图式 20 马钱子碱衍生物 63 的合成

Scheme 20 Synthesis of brucine derivative 63 
2005 年, Král 课题组 ${ }^{[40]}$ 用马钱子碱和芐基卤代烷修 饰的卟啉衍生物反应, 得到了两种四马钱子碱一卟啉衍 生物 66 和 67, 产率分别为 77\% 和 48\% (Scheme 21). 四 马钱子碱-卟啉衍生物含有多个芳香环, 能与其他含有 芳香环的化合物产生 $\pi-\pi$ 堆积作用; 化合物上含有多个 氧、氮杂原子, 可以和其他含有活泼氢的物质形成氢键; 卟啉环氮原子上带有氢, 也可以和其他含有氮、氧的化 合物形成氢键; 马钱子碱季铵部分带有正电, 可与带有 负电物质结合. 四马钱子碱一卟啉衍生物由于具有上述 多种性质, 可以作为甲醇、乙腈等溶剂的高效凝结 剂 ${ }^{[40 a]}$. 除此之外, 卟啉一马钱子碱衍生物在溶剂中还可 以通过非共价键作用选择性识别腺苷三磷酸(ATP)等单 核苷酸 ${ }^{[40 b]}$. ATP 等单核苷酸具有芳环且含杂原子的嘌呤 基团、带负电的磷酸基团, 且可以提供氢原子形成氢键. 单核苷酸这些特性和含有特定空间结构的四马钱子碱卟啉衍生物形成了互补, 通过非共价键作用实现了在 ADP 和 AMP 存在下对 ATP 的选择性识别. 由于卟啉衍 生物本身具有荧光性质, 它们与单核苷酸形成复合物 后, 可以用于核苷酸的化学传感研究 ${ }^{[40 b-40 d] . ~}$

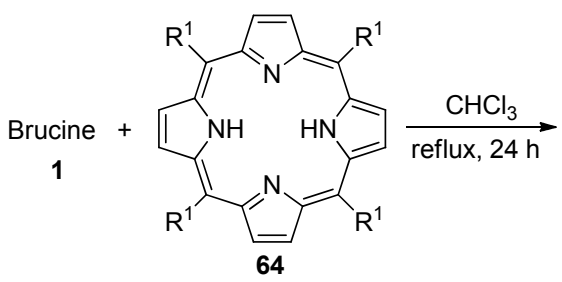<smiles>[R]c1ccc(-c2ccc([R])[nH]2)[nH]1</smiles>

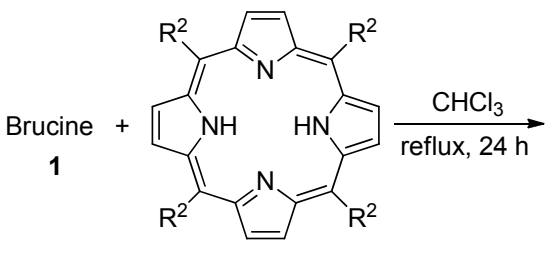

65

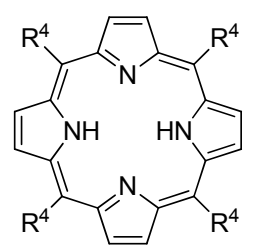

$6748 \%$ yield

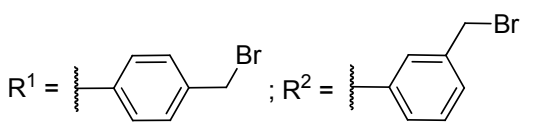

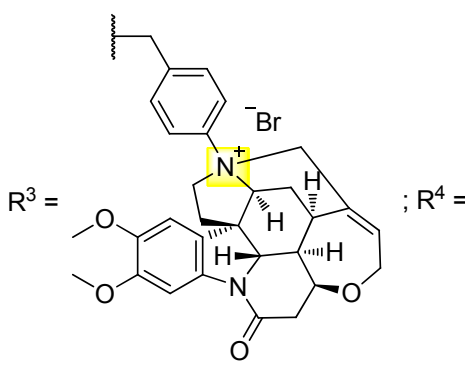

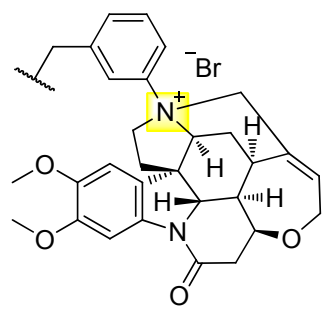

图式 21 四马钱子碱一卟啉衍生物的合成

Scheme 21 Synthesis of tetrabrucin-porphyrin derivatives

\section{4 马钱子碱 $\mathrm{C}=\mathrm{C}$ 双键参与的反应}

$\mathrm{C}=\mathrm{C}$ 双键具有还原和氧化双重性质. 此外, 双键
富有电子，具有一定的亲核性. 马钱子碱 $\mathrm{C}=\mathrm{C}$ 双键能 基于以上三种性质发生化学反应.

2009 年, Oh 课题组 ${ }^{[41 a]}$ 以四氧化锇为催化剂, 用 $N$ 甲基吗啉 $-N$-氧化物(NMO) $)^{[42]}$ 对马钱子碱进行了双羟化, 以 95\%的收率获得了衍生物 68 (Scheme 22).

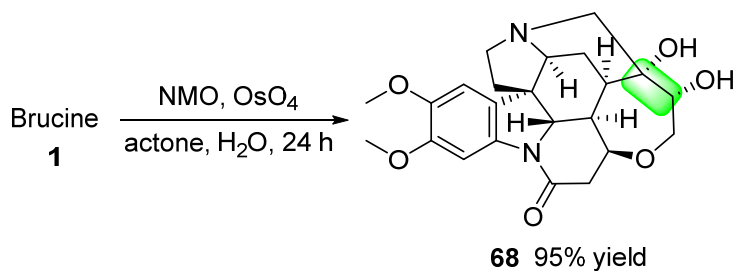

图式 22 马钱子碱的双羟基化反应

Scheme 22 Dihydroxylation of brucine

双羟化衍生物 68 上的氮原子依然有较强的亲核性, 可以和茮溴发生亲核取代反应，以 $82 \%$ 的收率得到相应 的季铵盐衍生物 69 (Scheme 23).

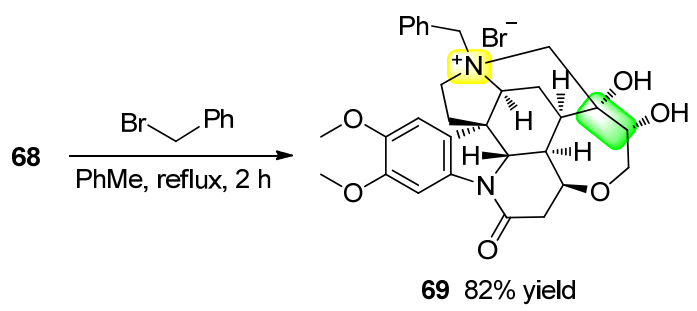

图式 23 马钱子碱双羟基化衍生物和芐溴的反应 Scheme 23 Reaction of dihydroxylated derivatives of brucine with benzyl bromide

68 中的羟基去质子化可以和乙酰氯反应, 得到两 种乙酰化的衍生物 70 和 71, 二者产率均为 $55 \%$ (Scheme 24). 这些马钱子碱衍生物可以作为手性配体, 用于过渡金属催化的不对称合成(见第 3.2 节 $)^{[4]}$.

68

(i) DMAP, pyridine

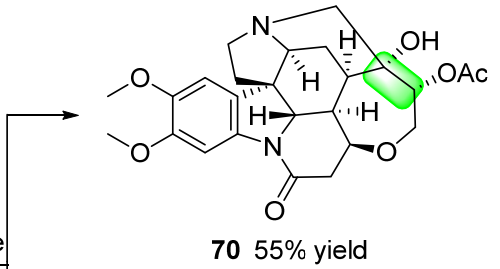

(ii) dropwise $\mathrm{AcCl}$

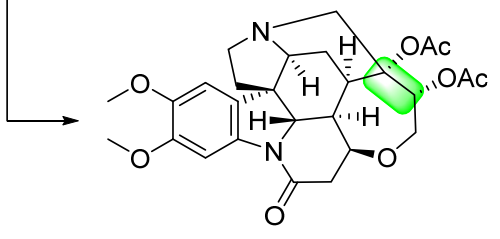

$7155 \%$ yield

图式 24 马钱子碱双羟基化衍生物和的乙酰化反应

Scheme 24 Acetylation of dihydroxylated brucine

2016 年, Hartwig 课题组 ${ }^{[43]}$ 以 Togni 试剂 $\mathbf{7 2}^{[44]}$ 为三 
氟甲基化试剂，四甲基硅基叠氮( $\mathrm{TMSN}_{3}$ )为叠氮化试剂, 实现了马钱子碱 $\mathrm{C}=\mathrm{C}$ 双键的双官能团化. Togni 试剂在 $\mathrm{Fe}$ (II)催化下产生亲电的三氟甲基自由基, 进而与 $\mathrm{C}=$ C 双键的较富电子一端连接, 得到的自由基中间体被 $\mathrm{TMSN}_{3}$ 捕获, 实现叠氮化. 在手性配体 73 的作用下, 该 反应实现了区域选择性和立体选择性的双重控制，以 $70 \%$ 的收率得到了单一构型的马钱子碱衍生物 74 (Scheme 25). 该方法同样适用于其他含有 $\mathrm{C}=\mathrm{C}$ 双键的 天然分子, 所得结构修饰产物可供药物篎选, 为药物发 现提供更多的机会.

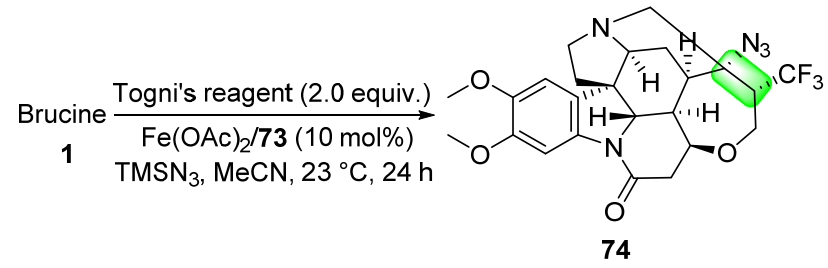

$70 \%$ yield, single isomer

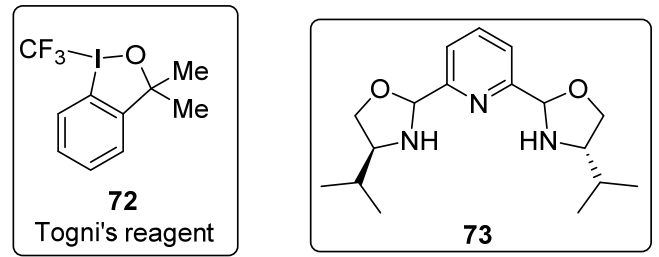

图式 25 马钱子碱的三氟甲基化叠氮化反应

Scheme 25 Trifluoromethylazidation of brucine

2019 年, Dydio 课题组 ${ }^{[45]}$ 用铂催化剂在高温高压下 实现了对马钱子碱 $\mathrm{C}=\mathrm{C}$ 双键的氢化反应. 在该反应中, 双键和梄键被同时氢化, 得到了 $22 \%$ 产率的马子碱的醇 类衍生物 75 (Scheme 26).

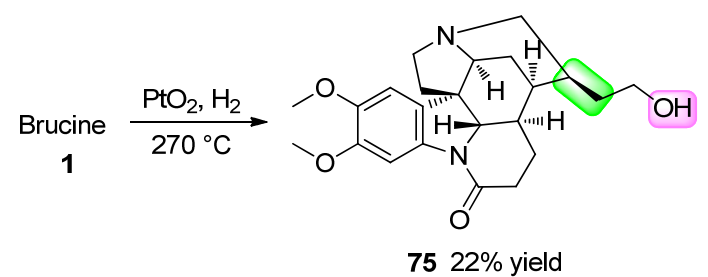

The absolute stereochemistry at the new stereocenter was assigned.

图式 26 马钱子碱的钯催化氢化反应

Scheme 26 Palladium-catalyzed hydrogenation of brucine

醇衍生物 75 可以在 $\mathrm{Pd}(\mathrm{II})$ 和 $\mathrm{Ru}(\mathrm{II})$ 催化剂的共同作 用下与卤代芳烃反应，得到了羟基 $\beta-\mathrm{C}-\mathrm{H}$ 键选择性芳 基化的产物 76, 产率为 33\% (Scheme 27). 对复杂产物 75 的成功修饰，突出了该双催化体系的合成应用价值.

\section{2 马钱子碱作为手性拆分试剂}

从马钱子属植物中提取的马钱子碱(1)、番木鳖碱 (2), 以及从金鸡纳亚科植物中提取的奎宁 (77, Quinine)、 奎尼丁(78, Quinidine)、辛可尼丁(79, Cinchonidine)、辛

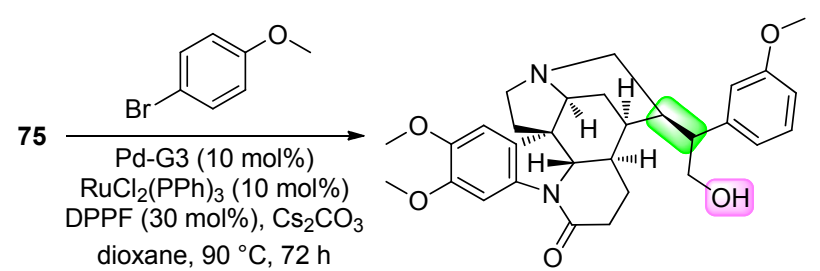

76

$33 \%$ yield, $>20: 1 d r$
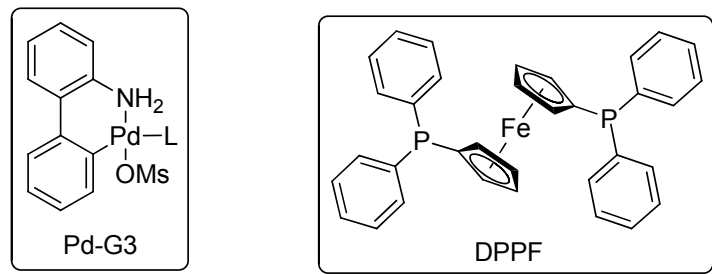

图式 27 马钱子碱衍生物 75 羟基的 $\beta-\mathrm{C}-\mathrm{H}$ 芳基化 Scheme 27 Arylation of the $\beta-\mathrm{C}-\mathrm{H}$ bond of the hydroxyl group in brucine derivative $\mathbf{7 5}$

可宁 $(\mathbf{8 0}$, Cinchonine)(图 6), 都是常见的具有光学活性 的天然生物碱. 这些手性生物碱可用于对羧酸、膦(磷) 酸、酚等酸性外消旋体进行拆分, 主要原因是: 首先, 碱 性的氮杂环结构可以和羧酸、膦(磷)酸、酚等酸性物质 反应，易生成相应的固体盐. 其次，含有的大极性官能 团和芳香环体系易在分子间产生范德华力、氢键、 $\pi-\pi$ 堆积效应等非共价作用. 由于不同马钱子碱盐之间非共 价作用程度不同，故在溶剂中的溶解度也不同，得以通 过结晶实现不同马钱子碱盐的拆分. 通过对马钱子碱盐 进行碱化、酸化处理，可拆分出酸性有机物。最后，它们 都含有多个手性中心和复杂并环、螺环或桥环的立体结

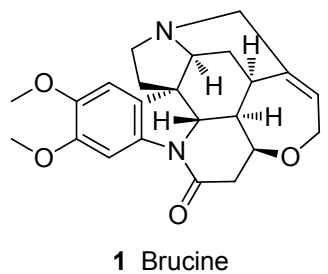

1 Brucine

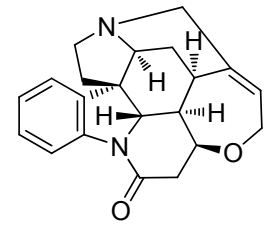

2 Strychnine<smiles>C=C[C@H]1CN2CCC1C[C@H]2[C@H](O)c1ccnc2ccc(OC)cc12</smiles>

77 Quinine<smiles>C=C[C@H]1CN2CC[C@H]1C[C@@H]2[C@H](O)c1ccnc2ccc(OC)cc12</smiles>

78 Quinidine<smiles>C=C[C@H]1CN2CC[C@H]1C[C@@H]2[C@H](O)c1ccnc2ccccc12</smiles>

79 Cinchonidine<smiles>C=C[C@H]1CN2CC[C@@H]1C[C@@H]2[C@H](O)c1ccnc2ccccc12</smiles>

80 Cinchonine

图 6 常用于手性拆分的马钱子属和金鸡纳树属生物碱 Figure 6 Application of strychnos and cinchona alkaloids in chiral resolution 
构. 天然的光学活性和独特的空间结构是拆分外消旋化 合物的重要诱因. 一些情况下, 仅仅用马钱子碱(1)并不 能完全实现两个对映异构体的拆分, 还需同时借助手性 碱 2、77 $\sim 80$.

早在 1916 年, Wren 和 Williams ${ }^{[46]}$ 就使用马钱子碱 对外消旋的苯基琥珀酸进行了拆分. 随后的数十年里, 马钱子碱常被用于拆分手性氨基酸 ${ }^{[47]}$ 和含有羧基的手 性药物分子 ${ }^{[48]}$. 此外, 早期还有报道使用马钱子碱直接 拆分手性醇 ${ }^{[49]}$ 和手性卤代烃 ${ }^{[50]}$ 的案例, 随着不对称合 成及手型拆分方法的多样化, 这些方法已不再是研究的 热点. 新世纪以来, 除了传统的拆分应用外, 马钱子碱 更多地被用于拆分手性配体和手性配体前体.

历经一百多年的研究和发展, 马钱子碱的手性应用 已数不胜数. Jaen ${ }^{[51]}$ 在 2001 年对马钱子碱以往的手性应 用进行了很好的总结, 本文主要对更新和更具有实际应 用价值的研究进展进行综述.

\section{1 对外消旋羧酸、膦(磷)酸和酚的拆分}

马钱子碱可用于拆分螺旋手性和轴手性羧酸或酚 类化合物. 2008 年, Wild 课题组对前人的方法 ${ }^{[52]}$ 进行了 改进, 更高效地实现了用马钱子碱对手性螺环化合物 81 的拆分 ${ }^{[22 b]}$. 首先, 将 81 和马钱子碱在乙醇溶液中回 流加热 $2 \mathrm{~h}$, 随后经过热过滤除去不溶杂质. 将滤液在 热油浴中缓慢冷却, $(S)$-羒酸与马钱子碱形成的盐 82 结 晶析出. 对盐 82 多次重结晶, 随后酸化处理可得 $(S)$-羧 酸 83. 对母液多步处理可得 $(R)$-羧酸 84 (Scheme 28). 将

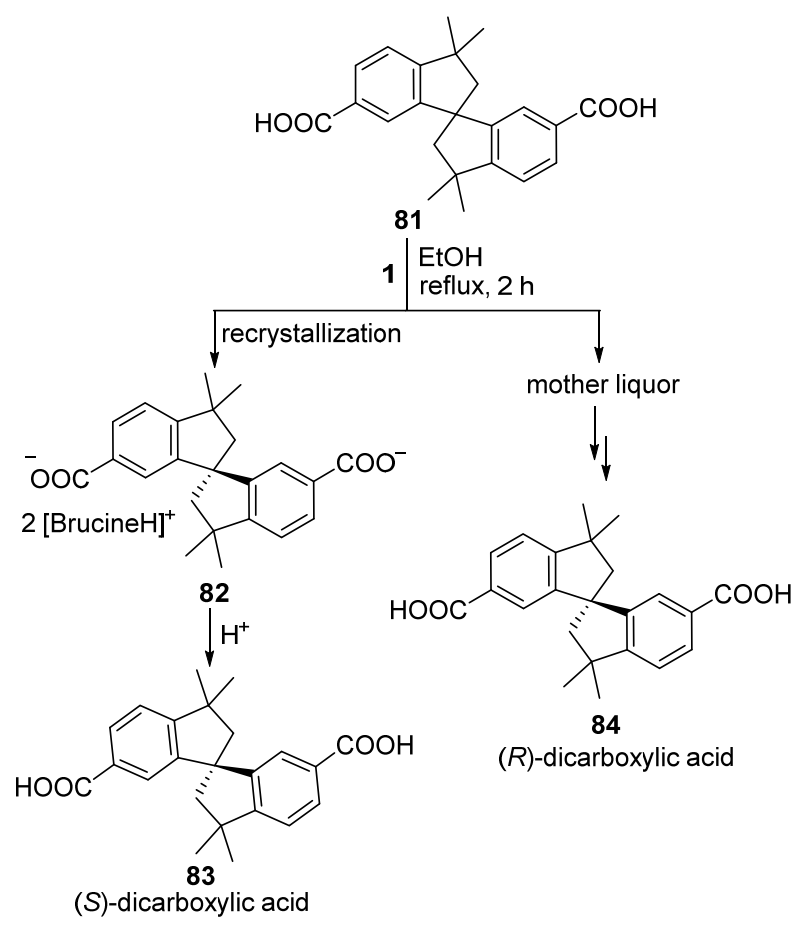

图式 28 手性酸 $\mathbf{8 1}$ 的拆分

Scheme 28 Resolution of chiral acid $\mathbf{8 1}$
每个 83 羧基都连接上多个氮原子的官能团, 可以得到 一个六齿的金属离子螯合剂 85 (Scheme 29).

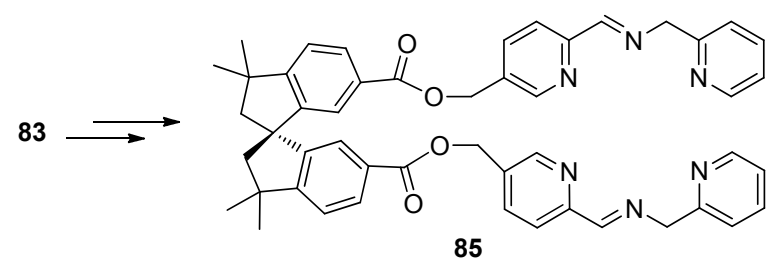

图式 29 由螺旋手性羧酸合成六齿配体

Scheme 29 Synthesis of hexadentate ligand from spiro chiral carboxylic acid

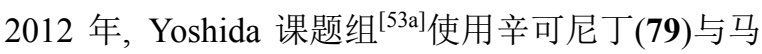
钱子碱(1)对外消旋芴酸衍生物 86 进行了拆分, 而手性 芴的酰胍类 (carbonyl guanidine) 衍生物 89 可作为 $5-\mathrm{HT}_{2 \mathrm{~B}}$ 和 5-HT 7 受体双重拮抗剂(Dual antagonist) (Scheme 30). 2014 年, Moritomo 课题组 ${ }^{[33 b]}$ 使用了 Yoshida 课题组的手 性拆分方法, 合成了一系列的酰胍类 $5-\mathrm{HT}_{2 \mathrm{~B}}$ 和 $5-\mathrm{HT}_{7}$ 受 体双重拮抗剂。

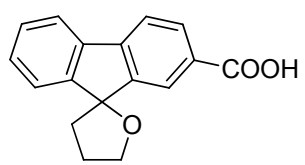

86

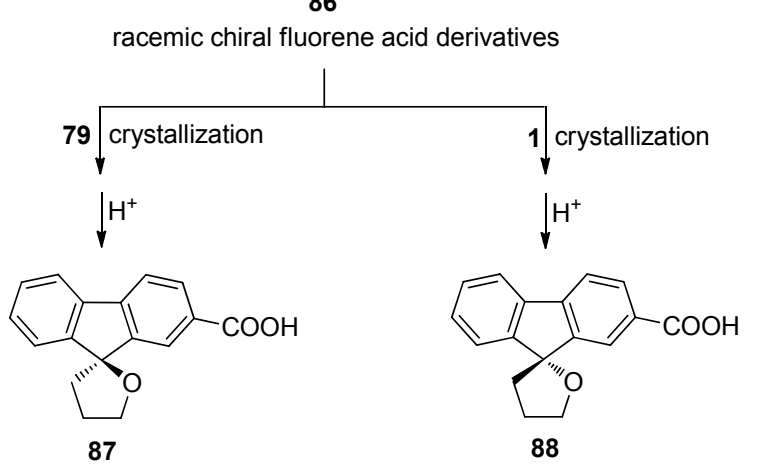

(S)-acid

(R)-acid

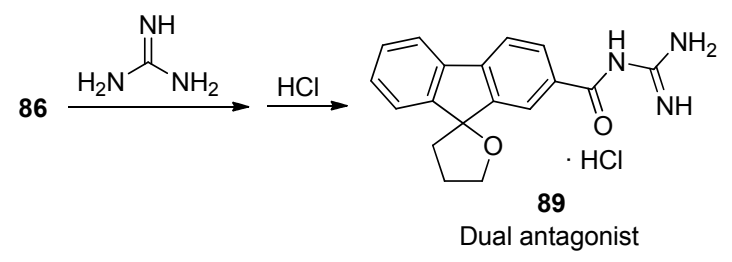

图式 30 双重拮抗剂 89 的合成

Scheme 30 Synthesis of dual antagonist 89

2004 年到 2005 年, Solladié 课题组 ${ }^{[54-54 b]}$ 用马钱子 碱拆分了轴手性联苯二甲酸 $\mathbf{9 0}$, 接着和长连烷基联二 苯酚反应生成相应的轴手性酯 92 (Scheme 31). 这种酯 类化合物可以作为向列相液晶(nematic liquid crystals)手 性掺杂剂(chiral dopants). 2014 年, Haino 课题组 ${ }^{[54 c]}$ 用同 样的方法拆分了外消旋体 90, 用以研究非对映超分子 复合物. 


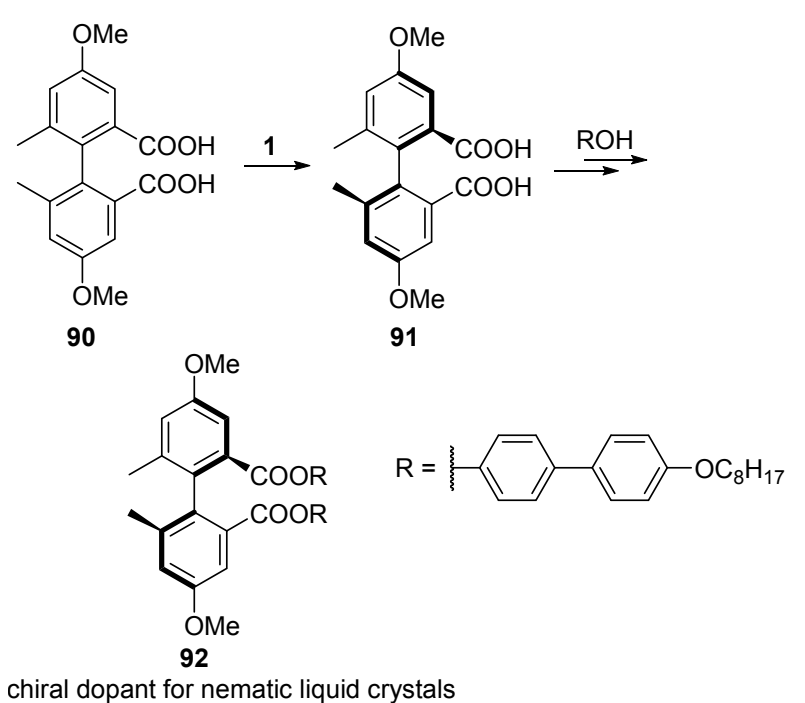

图式 31 向列相液晶手性掺杂剂 92 的合成

Scheme 31 Synthesis of chiral dopants 92 for nematic liquid crystals

2009 年, Polavarapu 课题组 ${ }^{[55 a]}$ 发现外消旋膦酸 93 能与马钱子碱生成两种光学活性的盐, 并测定了两种盐 的晶体结构. 由于两种盐结构不同, 在不同溶剂中析出 晶体的先后顺序也有差异. 在乙醇中盐 I (94)首先析出, 在二氯甲烷中盐 II (95)先结晶. 使用铝试剂 Red-Al ${ }^{[55 b]}$ 还原, 得到了两种单一光学活性的手性联菜酚 VANOL 96, 97 (Scheme 32).

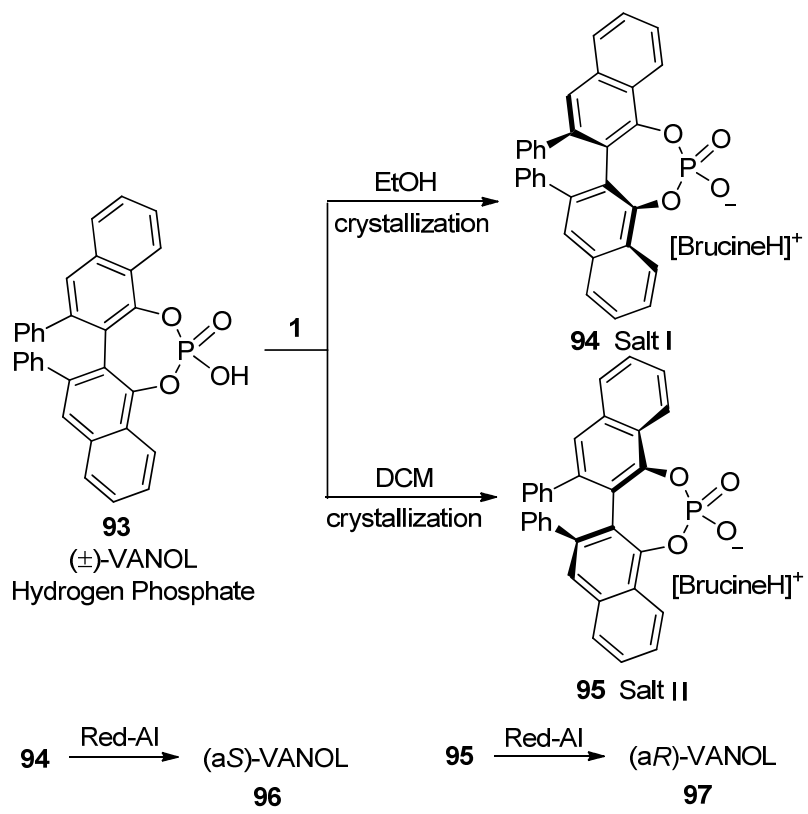

图式 32 手性膦酸 93 的拆分及衍生化

Scheme 32 Resolution of chiral phosphoric acid 93 and its derivatization

2002 年, Král 课题组 ${ }^{[56]}$ 开发了马钱子碱-硅胶复合 的手性识别支架 101 (Scheme 33). 该课题组用马钱子碱 和 6-溴己酸 $(98)$ 反应得到了相应的季铵盐衍生物 99 , 再
和 3-氨基丙基硅胶 100 缩合得到了带有正电荷的马钱子 碱一硅胶复合支架 101. 该支架可以作为色谱固定相，对 含有羧基结构的轴手性二䒺酚 102 和 103 进行拆分. 需 要注意的是，该拆分方法的作用机制为阴离子交换作 用，与直接用马钱子碱进行拆分的机制不同，并不涉及 季胺部分与酸性基团的作用.
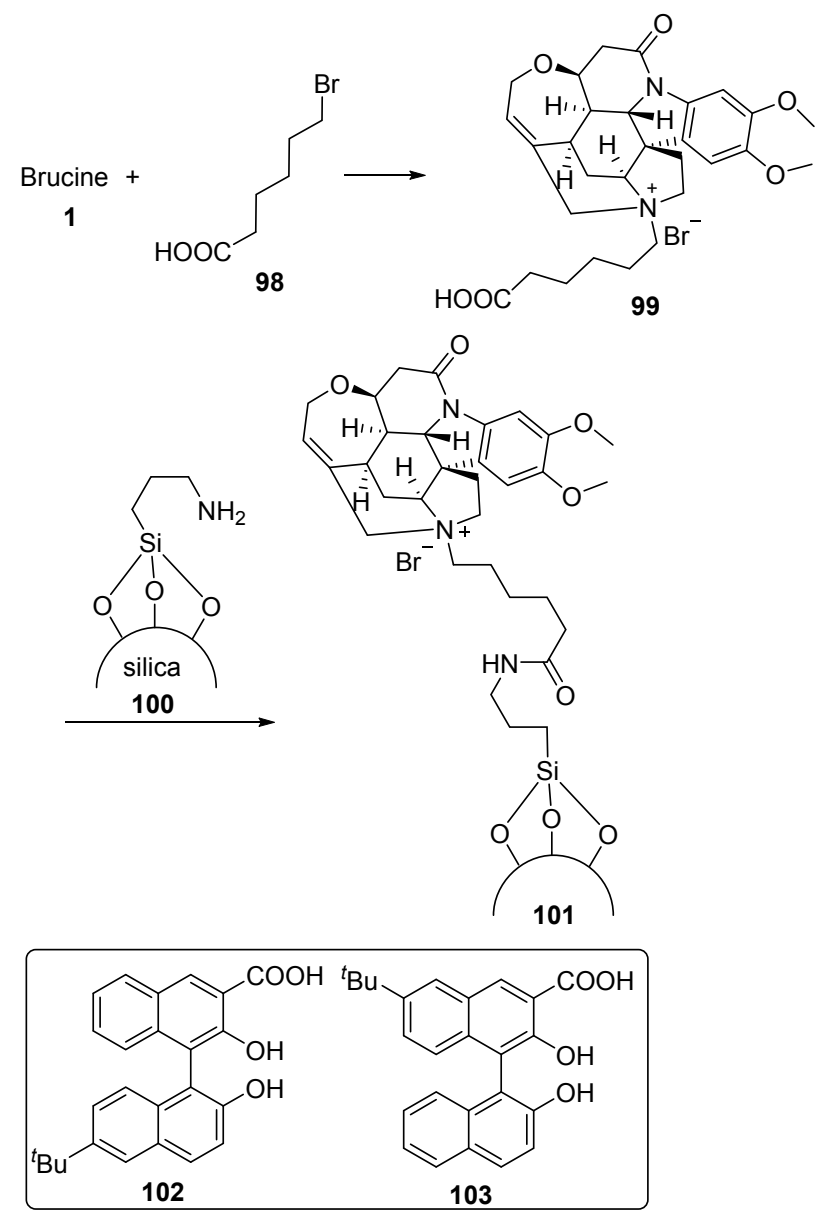

图式 33 手性识别支架 101 的合成

Scheme 33 Synthesis of chiral recognition scaffold 101

除了用手性色谱拆分轴手性联萗酚外，也可以直接 用马钱子碱拆分.

2009 年, Tanaka 和 Urbanczyk-Lipkowska 课题组 ${ }^{[57 a]}$ 实现了马钱子碱对含有两个羧基的联菜酚 104 的手性拆 分(Scheme 34). 两个羧基作为活性基团，在拆分过程中 起到与马钱子碱成盐的作用.

2016 年, Bedekar 课题组 ${ }^{[57 b]}$ 实现了对不含羧基结构 的手性联菜酚 107 的拆分(Scheme 35). 该拆分属于真正 意义上对酚类化合物的拆分, 菜-2,7-二酚部分的两个羟 基与马钱子碱叔胺部分通过氢键作用缔合。该拆分方法 操作简单，只需将 107 与马钱子碱在甲醇中回流，析出 的晶体为 108 与马钱子碱的缔合体，母液中含有未反应 的 109 . 
<smiles>CCC(CC)C(CC)C(=O)O</smiles>

图式 34 手性联䒺酚 104 的拆分

Scheme 34 Resolution of chiral binaphthol 104

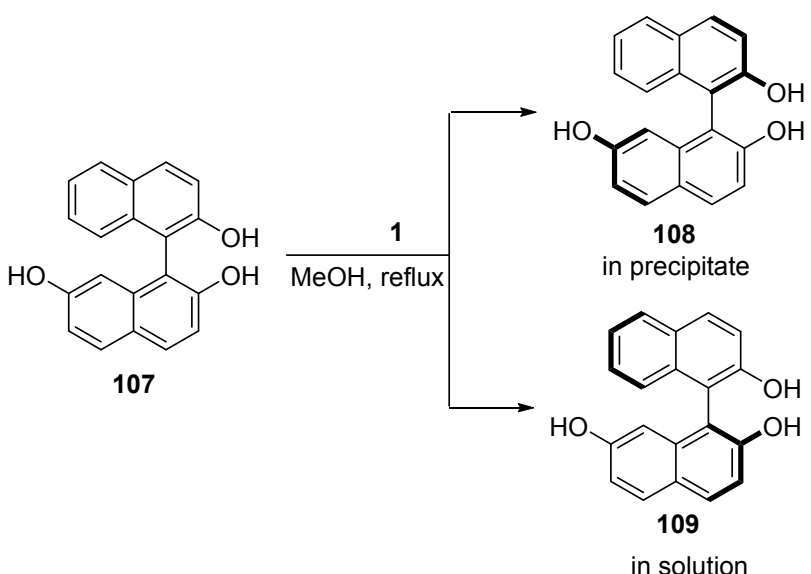

图式 35 手性联荎酚 107 的拆分

Scheme 35 Resolution of chiral binaphthol 107

使用马钱子碱还可以对其它手性羧酸进行拆分. 2004 年, Otto 课题组 ${ }^{[58]}$ 使用马钱子碱从外消旋的 $S$-芐 基- $N$-甲酰基- $\beta$-高半胱氨酸(110)中拆分出了 $S$-构型的对 映异构体 111. 去甲酰基之后可得 $(S)-S$-芐基- $\beta$-高半胱氨 酸, 该化合物经过多步反应之后可制得手性 $\beta$-磺酰内胺 112 (Scheme 36).

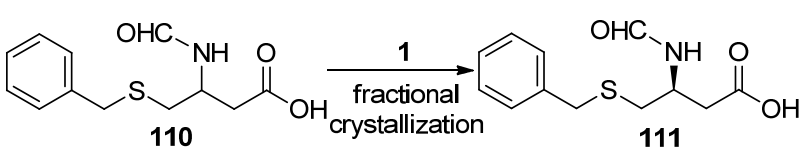

S-Benzyl-N-Formyl$\beta$-homocysteine

(S)-S-Benzyl- $\beta$-homocysteine

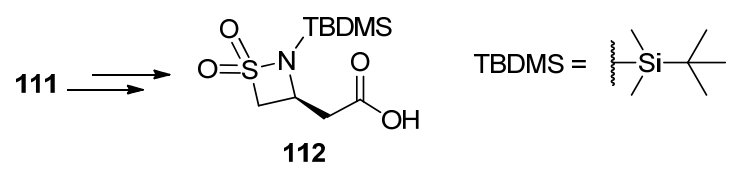

图式 36 手性 $\beta$-磺酰内胺 112 的合成 Scheme 36 Synthesis of chiral $\beta$-sulfonyl lactam 112 2008 年, Czarnocki 课题组 ${ }^{[59]}$ 将含有羧基的 $\gamma$-内酰胺
113 分别和马钱子碱、番木鳖碱(2)作用, 得到了 $2 S, 3 S$ 和 $2 R, 3 R$ 构型的对映异构体 114 和 115 (Scheme 37). 114 可以协助对外消旋醇进行拆分(详见第 2.2 节).

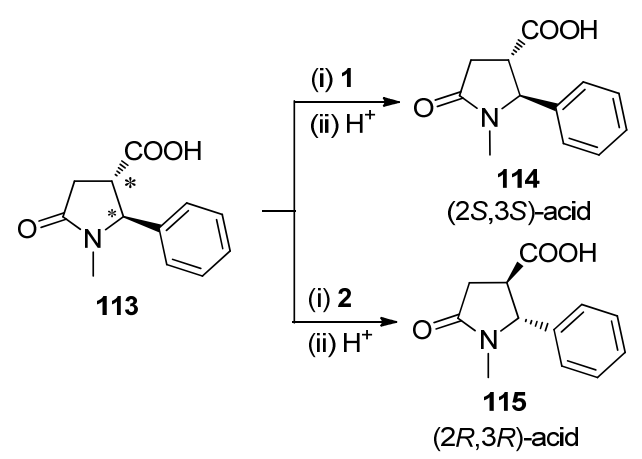

图式 37 手性酸 113 的拆分

Scheme 37 Resolution of chiral acid $\mathbf{1 1 3}$

2005 年, Doyle 课题组 ${ }^{[60]}$ 实现了对 trans-2-苯基环丙 基甲酸(116)的拆分(Scheme 38). 之后将 2-苯基环丙基 甲酸逐步转化为咪唑酮类衍生物 119 和 120 (Scheme 39), 可以作为 $\mathrm{Rh}(\mathrm{II})$ 催化剂配体用于铑卡宾参与的不对 称 $\mathrm{C}-\mathrm{H}$ 键官能团化反应和醛与双烯的不对称杂-DielsAlder 环加成反应.
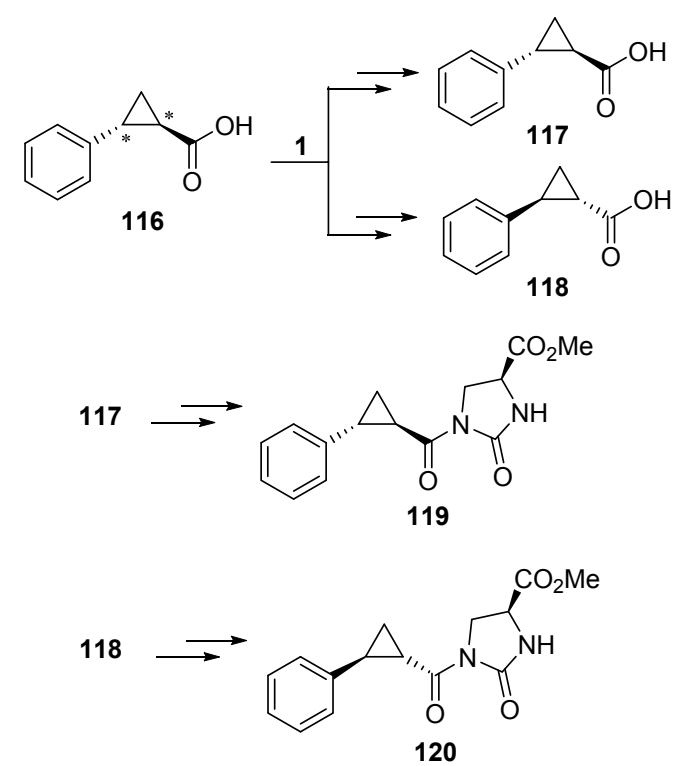

图式 38 2-苯基环丙基甲酸的拆分及衍生化

Scheme 38 Chiral resolution and derivatization of trans-2phenylcyclopropane-1-carboxylic acid

2011 年, White 课题组 ${ }^{[61]}$ 用马钱子碱拆分出了桥环 结构的手性二甲酸 122 , 之后逐步合成了 $C_{2}$-对称的四 齿手性配体 123 (Scheme 39), 可用于 Cr(III)催化的醛与 双烯的不对称杂-Diels-Alder 环加成反应和醛与烯丙基 溴的不对称 Nozaki-Hiyama-Kishi 反应. 


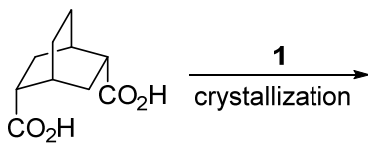

121

(士)-dicarboxylic acid<smiles></smiles>

123

(+)-diiminephenol

图式 39 手性酸 121 的拆分及衍生化

Scheme 39 Resolution and derivatization of chiral acid $\mathbf{1 2 1}$

2007 年, Carlier 课题组 ${ }^{[62]}$ 用马钱子碱拆分手性酸 124 后，用相应的羧酸 125 合成了手性格氏试剂 127 (Scheme 40)

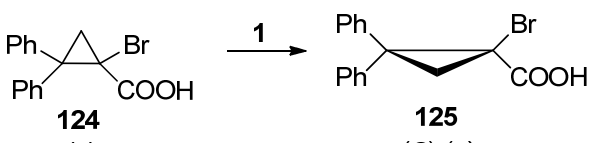

$( \pm)$

$(S)-(+)$

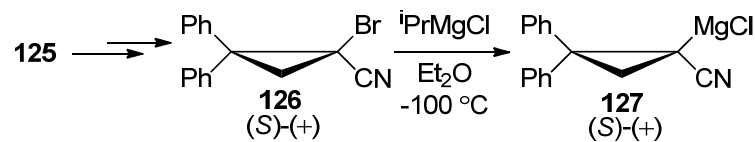

图式 40 手性格氏试剂 127 的合成

Scheme 40 Synthesis of chiral Grignard reagent 127

2014 年, 董广涁课题组 ${ }^{[63]}$ 使用马钱子碱拆分了手 性酸 128 (Scheme 41), 用以研究酮类化合物 $\alpha-\mathrm{C}-\mathrm{H}$ 键 活化反应中的立体效应.<smiles>O=C1CCC(C(=O)O)C1</smiles>

$$
\underset{\text { recrystallization } 4 \text { times }}{\mathrm{H}_{2} \mathrm{O} \text {, reflux }}
$$

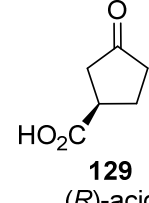

$(R)$-acid

图式 41 手性羧酸 128 的拆分

Scheme 41 Resolution of chiral acid 128

Thiele's 酸(130) 是一种具有独特刚性夹角的分子, 又因为其两端的羧基易于衍生化, 故可以利用 130 制作 应用于超分子或生物化学领域的分子支架 ${ }^{[64]} .2017$ 年, Wulff 课题组 ${ }^{[65]}$ 笁选了辛可尼丁 (79)、 $L$-色氨酸乙酯、 $L$ 酪氨酸酰肼等手性胺类化合物, 均无法有效拆分外消旋 的 Thiele's 酸. 最终, 使用马钱子碱作为拆分试剂时, (一)-Thiele's 酸(131)与两分子马钱子碱以盐的形式结晶 析出, $(+)$-Thiele's 酸(132)保留在了母液中. 最后进行酸
化处理，实现了对 130 的手性拆分(Scheme 42).

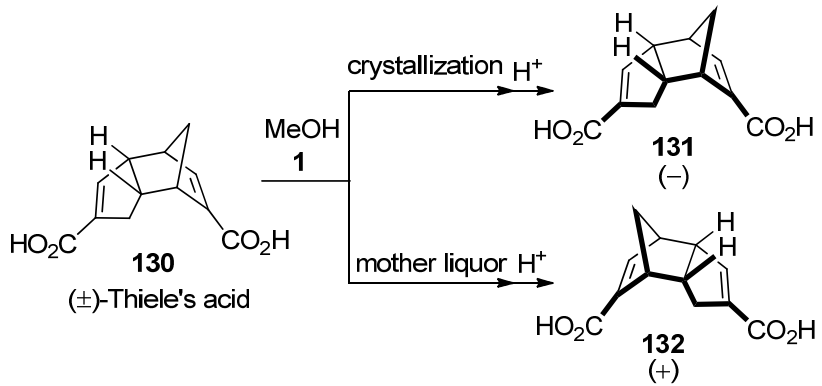

图式 42 外消旋 Thiele's 的的拆分

Scheme 42 Resolution of racemic Thiele's acid

2017 年, 姚祝军课题组 ${ }^{[66]}$ 用马钱子碱和奎宁(77)配 合拆分了外消旋的 2,3-二甲基酒石酸(133). 在乙醇中, 以奎宁(77)为拆分试剂可以得到 $(2 S, 3 S)$-2,3-二甲基酒石 酸(134); 在水溶液中, 以马钱子碱为拆分试剂可以得到 $(2 R, 3 R)-2,3$-二甲基酒石酸(135). 被拆分的 2,3-二甲基酒 石酸在手性拆分、手性催化等领域具有一定的应用潜力.

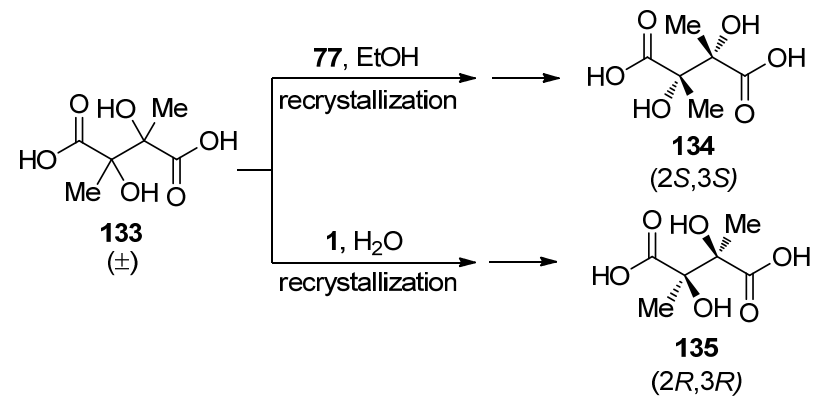

图式 43 外消旋 2,3-二甲基酒石酸的的拆分

Scheme 43 Resolution of racemic 2,3-dimethyl tartaricacid

\section{2 对外消旋醇的策略性拆分}

由于醇类不能与手性生物碱成盐，故需要一定的策 略对醇修饰. 目前对醇的拆分主要有三种策略. 第一, 将外消旋的醇和手性酸反应，制备成非对映异构的酯， 经分离、水解，也可以间接地拆分对映异构的醇. 例如, 利用 Scheme 37 中的 $(2 S, 3 S)$-羧酸 114 和外消旋醇反应可 以得到一对非对映异构的酯，通过柱层析的方式可使二 者分离; 再经过皇化反应分别得到一对互为对映异构体 的醇 ${ }^{[59]}$. 第二，部分特定结构的醇可以通过与手性生物 碱的氢键作用，实现直接拆分. 第三，将醇和邻苯二甲 酸䣶反应，得到邻苯二甲酸半酯. 通过用手性生物碱拆 分邻苯二甲酸半酯，再水解得醇，间接地实现了对醇的 对映异构体的拆分. 这是最常用的方法. 由于第一种方 法不涉及马钱子碱的应用，第二种方法限制性强且鲜有 报道，故本节仅介绍最后一种策略.

1926 年, Kenyon ${ }^{[67]}$ 将利用手性生物碱分离邻苯二 甲酸半酯，水解半酯间接得到手性醇的方法公布，并对 
该方法做了详尽的描述(Scheme 44). 首先用外消旋的 1甲基庚醇(137)和邻苯二甲酸䣶(136)反应得到相应的半 酯 138, 接着用马钱子碱与半酯成盐 139 , 实现拆分. 使 用盐酸可以使马钱子碱解离, 经过皇化水解得到了两种 互为对映异构体的脂肪醇 140 和 141.

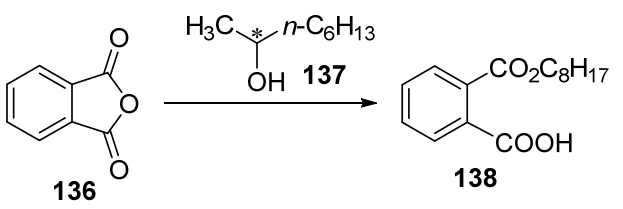

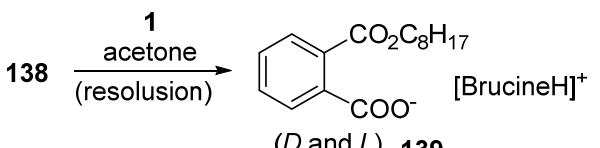

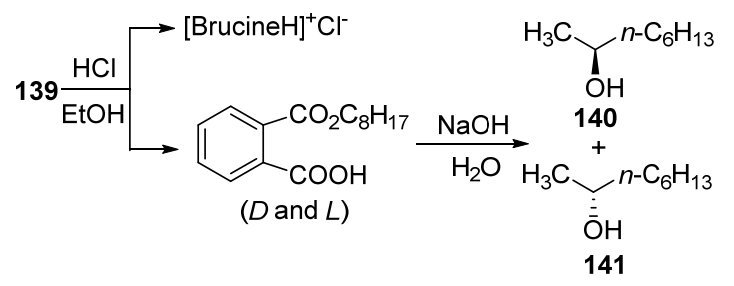

图式 44 手性醇 137 的拆分

Scheme 44 Resolution of chiral alcohol 137

自 Kenyon 公布他的方法之后的 80 年里, 该方法被 广泛地应用于多种外消旋醇的拆分, 在 Jaen 的综述中已 有所列举 ${ }^{[1]}$. 更值得关注的是, 也可以使用该方法拆分 邻苯二甲酸半酰胺, 随后经过水解, 得到手性伯胺化合 物 ${ }^{[68]}$.

\section{3 对外消旋药物的拆分}

马钱子碱可以对外消旋药物进行拆分, 该方法同样 要求药物分子含有酸性的羧基或酚羟基. 虽然该部分实 质上还是对羧酸和酚的拆分(第 2.1 节), 但鉴于目前药 物合成在有机化学研究中的重要地位, 本文将外消旋药 物的拆分单独列出来.

5,5-二苯乙内酰脲 $(\mathbf{1 4 5}$, PHT) 是一种抗惊厥药物, 在生物体内可代谢成一个苯基对位被羟基化的衍生物 (142, 简称 HPPH). 1975 年, Claesen 课题组 ${ }^{[69]}$ 用马钱子 碱对 HPPH 进行了手性拆分, 研究了相关的生物代谢作 用(Scheme 45). 2004 年, Vogel 课题组 ${ }^{[696]}$ 实现了对 HPPH 的人工合成, 并用 Claesen 课题组的方法进行了手性拆 分.

2003 年, Nielsen 课题组 ${ }^{[70]}$ 实现了对抑菌药山芬霉 素(146, Saphenamycin)的全合成, 使用马钱子碱拆分出 了(一)-山芬霉素(147) (Scheme 46). 通过对其马钱子碱 盐的 $\mathrm{X}$ 光衍射分析, 确定了所得(一)-山芬霉素为 $R$ 构 型.

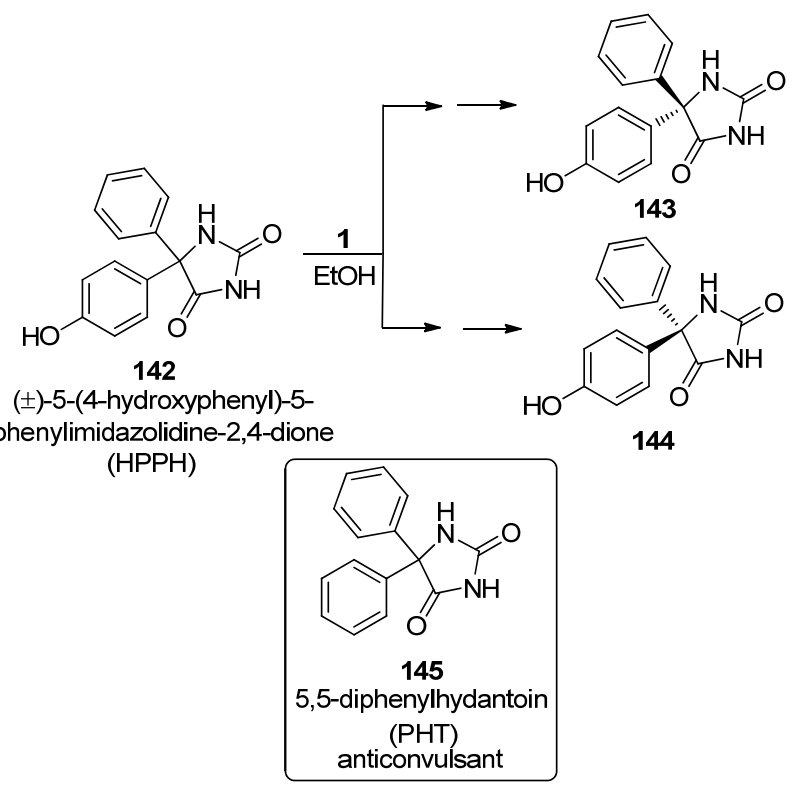

图式 45 手性 HPPH 142 的拆分

Scheme 45 Resolution of chiral HPPH 142

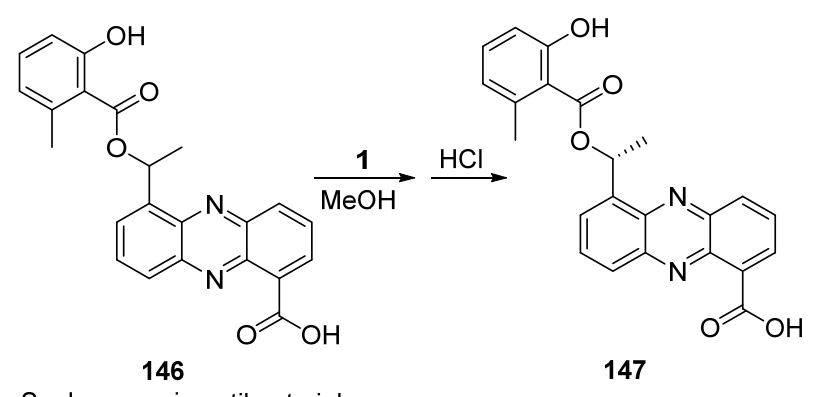

Saphenamycin antibacterial

$(R)-(-)$-Saphenamycin

图式 46 外消旋山芬霉素的拆分

Scheme 46 Resolution of racemic compounds

2005 年, Challenger 课题组 ${ }^{[71]}$ 合成了内皮素怙抗剂 UK-350,926 (148). 在热丙酮中可结晶出 $R$ 型异构体的 马钱子碱盐, 浓缩母液可以提取出 $S$ 型异构体 $\mathbf{1 5 0}$ (Scheme 47).
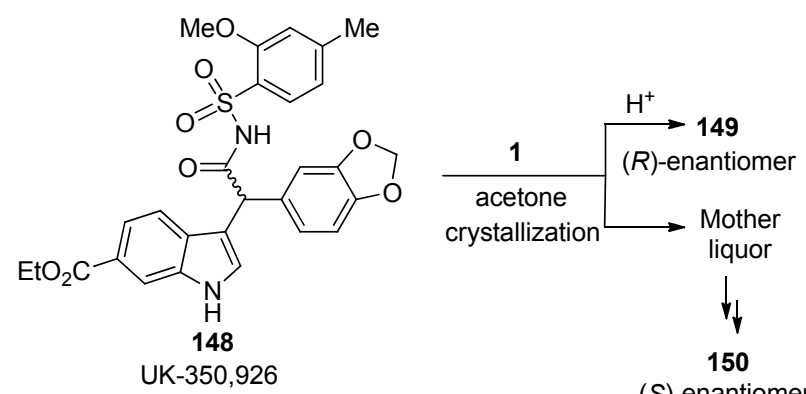

图式 47 内皮素拮抗剂 UK-350,926 的拆分

Scheme 47 Resolution of endothelin antagonist UK-350,926

2009 年, Kim 课题组 ${ }^{[72]}$ 使用两种不同的生物碱, 实 现了对抗炎镇痛药依托度酸(151, Etodolac)外消旋体的 
拆分. 依托度酸与辛可尼丁(79)生成盐, 结晶酸化得到 药物活性较低的(一)-依托度酸(152). 与之相反, 与马钱 子碱作用得到了比外消旋体药物活性更高的 $(+)$-依托 度酸(153)(Scheme 48).

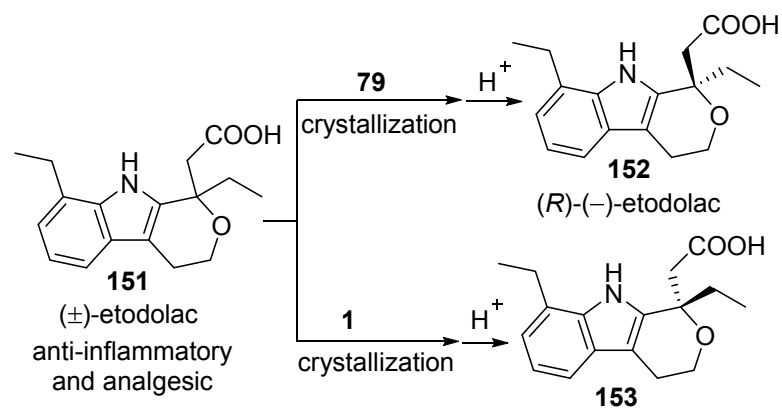

(S)-(+)-etodolac

图式 48 外消旋依托度酸的拆分

Scheme 48 Resolution of racemic etodolac

2012 年, Kuo 课题组 ${ }^{[73]}$ 合成了可作为神经毒素的手 性硫代膦酸酯. 该课题组将硫代膦酸 154 和马钱子碱溶 于热的丙酮溶剂中, 冷却后 $S$ 构型的硫代膦酸马钱子碱 盐 155 以固体析出, $R$ 构型的盐 156 被保留在溶液中, 将 溶液蒸发得到了两种构型的粗盐. 将两种粗盐分别溶于 氢氧化钠的醇溶液中, 加水会使马钱子碱固化析出. 分 别用四氯化碳洗涤后, 水相用盐酸酸化使硫代膦酸游 离. 用二氯甲烷分别萃取水相后, 减压浓缩可得一对硫 代膦酸对映异构体 157 和 158. 使用二环己基胺(160)稳 定硫代磷酸 157 后, 用碘乙烷乙基化得到手性的硫代膦 酸酯 159 (Scheme 49).

\section{3 作为碱、手性配体、手性催化剂或手性助剂 的应用}

\section{1 作为碱参与的反应}

马钱子碱是天然生物碱, 与质子酸结合生成盐是其 基本性质，此处不再赘述. 马钱子碱盐大多具有固定的 晶型, 非固体的酸可以通过与马钱子碱成盐来确定构 型 ${ }^{[74]}$. 此外马钱子碱还可以作为催化剂, 参与碱催化的 有机化学反应 ${ }^{[75]}$. 由于马钱子碱作为有机碱的非手性 应用并不是重点, 本小节仅介绍一例.

2019 年, Gates 课题组 ${ }^{[74 b]}$ 用马钱子碱对五配位的有 机膦羧酸 161 去质子化, 得到了与马钱子碱成盐的六配 位膦化合物 162. 通过 X 射线衍射确定了所合成化合物 的立体结构 (Scheme 50). 这种六配位的膦化合物负离 子是潜在的烯烃阳离子聚合引发剂 ${ }^{[74 b]}$.

\section{2 作为手性配体的应用}

2002 年, Yamamoto 课题组 ${ }^{[76]}$ 以马钱子碱为手性配 体, 在实现了芳基铅(IV)化合物 164 对 3,5-二甲基苯酚

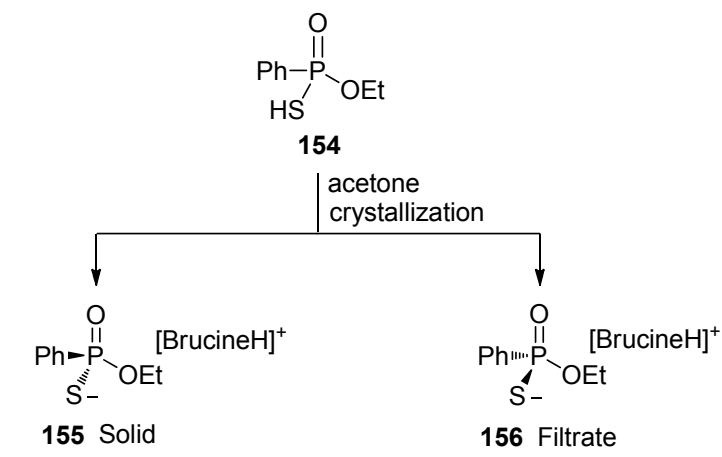

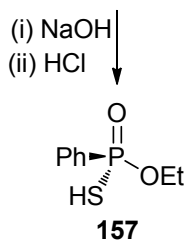

$(R)$-phosphonothioic acid

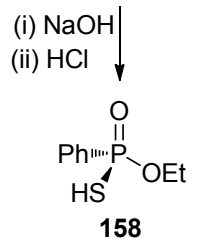

(S)-phosphonothioic acid

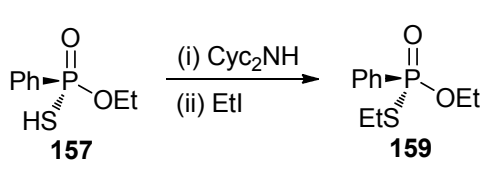

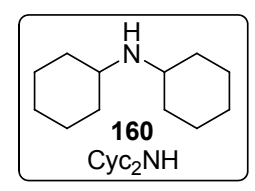

图式 49 神经毒素手性硫代膦酸酯 159 的合成 Scheme 49 Synthesis of chiral phosphonothioate 159 as neurotoxin

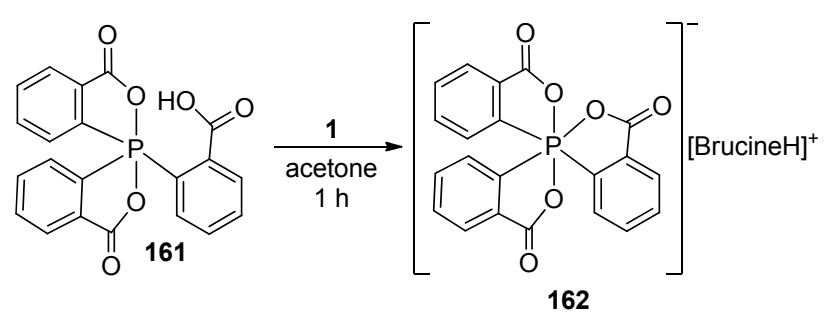

图式 50 六配位膦化合物 162 的合成

Scheme 50 Synthesis of hexacoordinated phosphorus 162

的高效不对称双官能团化反应，几乎以定量的产率得到 了酚 165 (Scheme 51). 马钱子碱通过与铅(IV)配位起到 手性诱导效果，对应异构体过剩(enantiomeric excess, $e e$ )值为 $61 \%$.

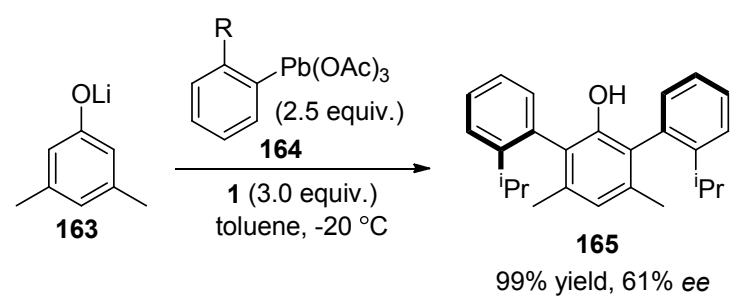

图式 51 3,5-二甲基苯酚的不对称双官能团化

Scheme 51 Asymmetric bifunctionalization of 3,5-dimethylphenol

2009 年到 2010 年, Oh 课题组 ${ }^{[41]}$ 用马钱子碱双差基 化的衍生物 68 作为手性配体, 用不同金属催化剂和相 
同的底物反应，得到了对映选择性不同的产物. 由此推 测不同金属和马钱子碱双着基化衍生物的配位方式不 同. 用 $\operatorname{Ag}(\mathrm{I})$ 为催化剂时, 有两分子马钱子碱双差基化 衍生物作为配体, 且只有氮原子和银原子配位 (166); 以 $\mathrm{Cu}(\mathrm{I})$ 和 $\mathrm{Cu}(\mathrm{II})$ 为催化剂时, 氮原子和氮 $\beta$ 位氧原子参与 络合(167，169); 而每分子的马钱子碱双羟基化衍生物 可以和两个 $\mathrm{Zn}(\mathrm{II})$ 原子配位(168) (Scheme 52).

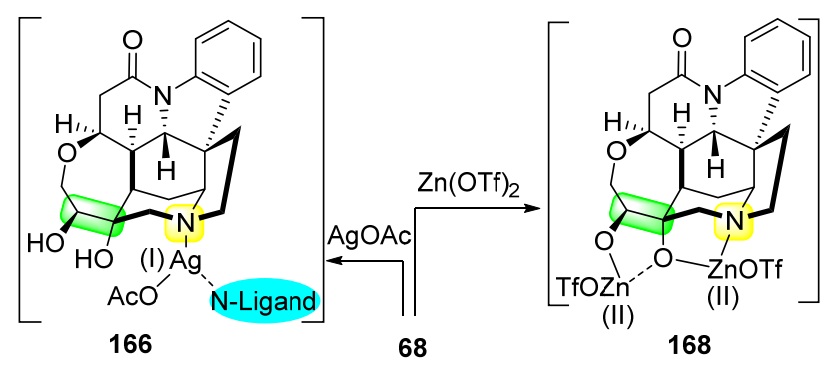

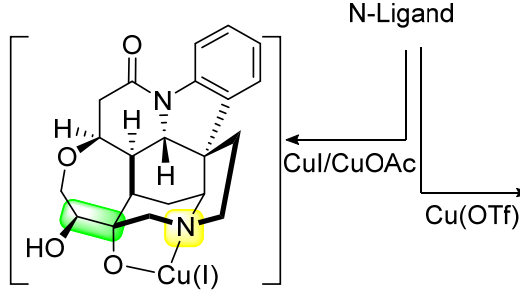

167

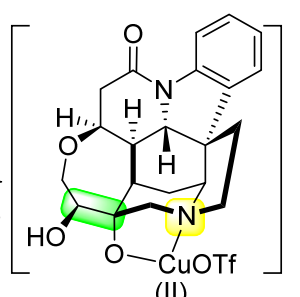

(II)
图式 52 不同金属离子和马钱子碱衍生物的络合形式 Scheme 52 Complexing forms of different metal ions and brucine derivatives

2009 年, $\mathrm{Oh}$ 课题组 ${ }^{[41 \mathrm{a}]}$ 用 $\mathrm{Ag}(\mathrm{I})$ 或 $\mathrm{Cu}(\mathrm{I})$ 为催化剂, 马 钱子碱双着基化衍生物作为配体, 实现了氮杂 1,3-偶极 化合物对 $\mathrm{C}=\mathrm{C}$ 双键的不对称环加成反应(Scheme 53). 当使用 $\operatorname{Ag}(\mathrm{I})$ 催化剂 166 时, 以较好的立体选择性得到 构型为 $2 S, 4 S, 5 R$ 的产物 172, 反应收率为 $79 \%$, ee 值为 $74 \%$. 当使用 $\mathrm{Cu}(\mathrm{I})$ 催化剂 167 时, 能够以极高的对应选 择性和极高的产率获得构型为 $2 R, 4 R, 5 S$ 的产物 $\mathbf{1 7 3}$, 产 率和 $e e$ 值分别为 $98 \%$ 和 $95 \%$.

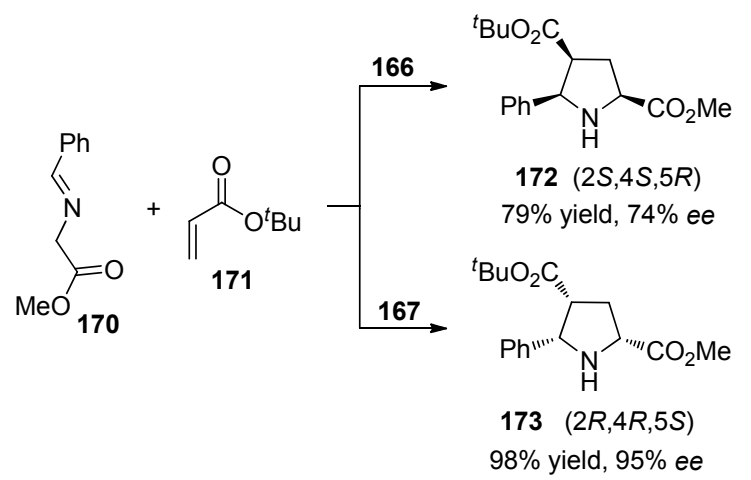

图式 53 化合物 170 和烯丙酸叔丁酯(171)的不对称环加成反 应

Scheme 53 Asymmetric cycloaddition of compound $\mathbf{1 7 0}$ with tert-butyl acrylate (171)
同年, $\mathrm{Oh}$ 课题组 ${ }^{[41 b]}$ 使用 $\mathrm{Cu}(\mathrm{I})$ 或 $\mathrm{Zn}(\mathrm{II})$ 为催化剂, 实现了硝基甲烷(175) 与醛 174 的不对称加成反应 (Scheme 54). 以 2-呋喃甲醛为底物参与反应, 使用 $\mathrm{Cu}(\mathrm{I})$ 催化剂 167 可得到 $S$ 构型产物 176, 产率为 $82 \%, e e$ 值高达 97\%. 使用 $\mathrm{Zn}(\mathrm{II})$ 为催化剂时，可得到 $R$ 构型的 产物 177 , 产率和 ee 值分别为 $88 \%$ 和 $90 \%$.

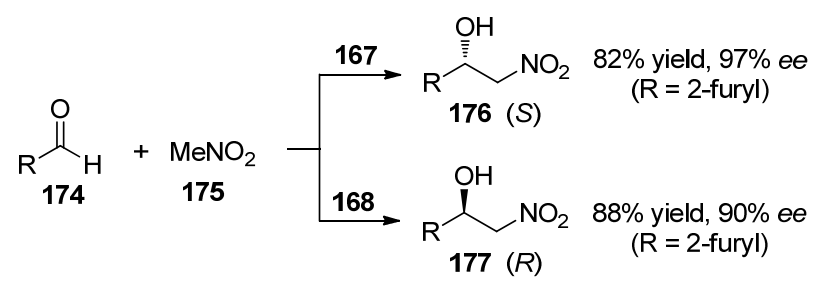

图式 54 硝基甲烷与醛 $\mathbf{1 7 4}$ 的不对称加成反应 Scheme 54 Asymmetric addition reaction of nitromethane with aldehyde 174

2010 年, $\mathrm{Oh}$ 课题组 ${ }^{[41 \mathrm{c}]}$ 以 $\mathrm{Cu}(\mathrm{II})$ 为催化剂, 实现了吲 哚类化合物 178 与硝基烯烃 179 的高对映选择性加成 (Scheme 55). 当 $\mathrm{R}^{1}$ 为氢且 $\mathrm{R}^{2}$ 为苯基时，能够以 $50 \%$ 的 反应收率和 $86 \%$ 的 $e e$ 值获得 $S$ 构型产物 $\mathbf{1 8 0}$.

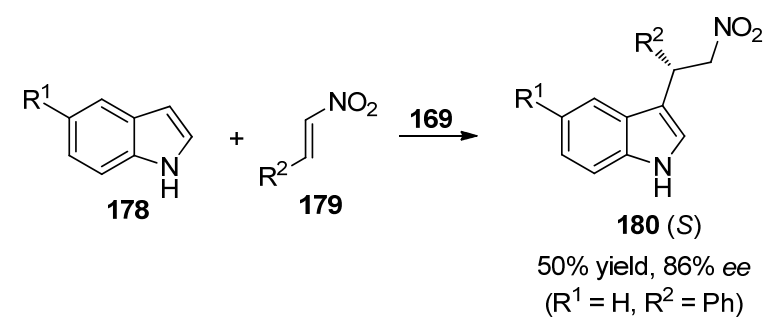

图式 55 吲哚类化合物与硝基烯烃的对映选择性加成 Scheme 55 Enantioselective addition of indoles and nitroalkenes

\section{3 作为手性催化剂或手性助剂的应用}

1904 年, Marckwald ${ }^{[77 a]}$ 用马钱子碱作催化剂, 实现 了 2-甲基-2-乙基丙二酸(181)在高温下的不对称去羰基 化反应(Scheme 56). 在该反应中, 质子化的马钱子碱季 铵盐中间体 182 是手性质子源. 1987 年, Toussaint, Capdevielle 和 Maumy ${ }^{[77 b]}$ 用 $\mathrm{Cu}(\mathrm{I})$ 和马钱子碱为催化剂, 实现了苯基丙二酸单酯(184)在温和条件下的不对称去 羰基化反应(Scheme 56). 上述两种产物的光学纯度 (optical purity, op)值均为在 $10 \%$ 左右.

1985 年, Mikołajczyk 课题组 ${ }^{[78]}$ 以马钱子碱为手性 助剂实现了亚磺酸酯 187 的不对称合成. 在该反应中, 具有手性和亲核性的马钱子碱与格氏试剂形成了手性 络合物 ${ }^{[79]}$, 接着和亚硫酸二酯 186 发生加成-消除反应, 以 $84 \%$ 的收率得到 $R$ 构型的亚磺酸酯 $187, e e$ 值为 $62 \%$ (Scheme 57). 

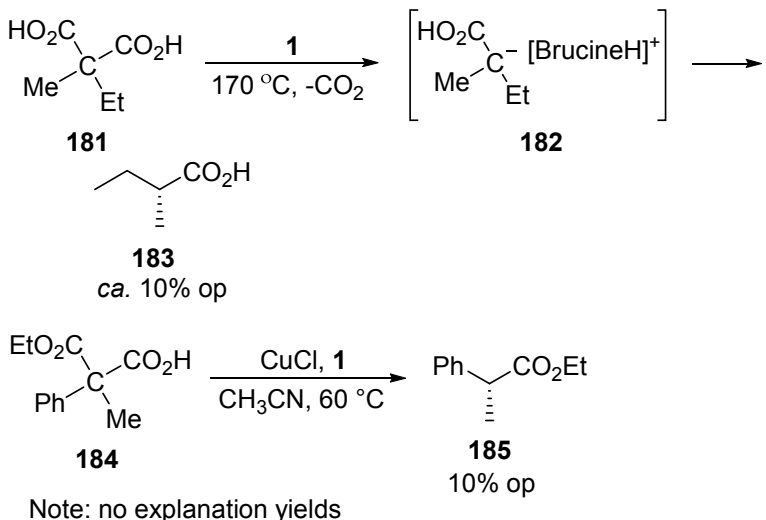

图式 56 马钱子碱作用下的不对称去羰基化反应

Scheme 56 Asymmetric decarbonylation under the action of brucine

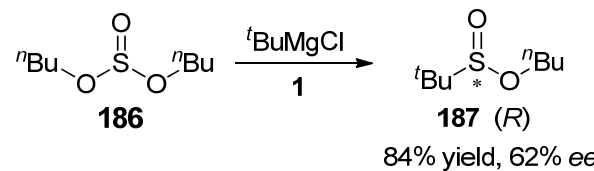

图式 57 光学活性亚磺酸酯 $\mathbf{1 8 7}$ 的合成

Scheme 57 Synthesis of optically active sulfinate $\mathbf{1 8 7}$

2009 年, Kolesińska 课题组 ${ }^{[80]}$ 用马钱子碱和 2氯-4,6-二甲氧基-1,3,5-三嗪(189)反应, 得到了能够活化 单一光学构型氨基酸的手性助剂 190. 使用助剂 190 实 现了在反应过程中将外消旋的氨基酸 191 进行拆分, 进 而与另一分子氨基酸 194 缩合成二肽 195 (Scheme 58). 该反应产物对应异构体浓度比(enantiomeric ratio, er)值 最高可达 99.6：0.4 ( $D$ 构型 $: L$ 构型).

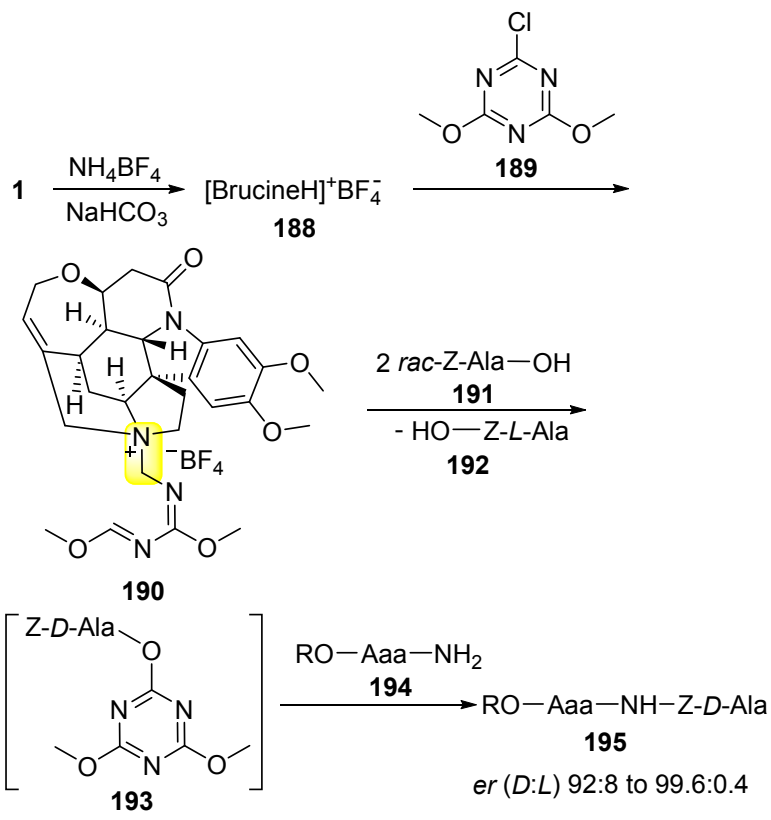

图式 58 二肽 195 的合成 Scheme 58 Synthesis of dipeptide 195
2010 年, Kimachi 课题组 ${ }^{[81]}$ 用对三氟甲基苠氯(196) 和马钱子碱反应得到了铵盐中间体 197 , 该中间体与苯 甲醛发生 Darzens 反应生成 $S, S$ 构型的环氧化合物 198. 该反应依托马钱子碱铵盐中间体的光学活性和空间位 阻，实现了对映和非对映选择性的双重控制 (Scheme 59). 该反应产物的非对映异构体浓度比(diastereomeric ratio, $d r$ ) 值为 $17 ： 83$ (cis：trans),ee 值为 65\%.

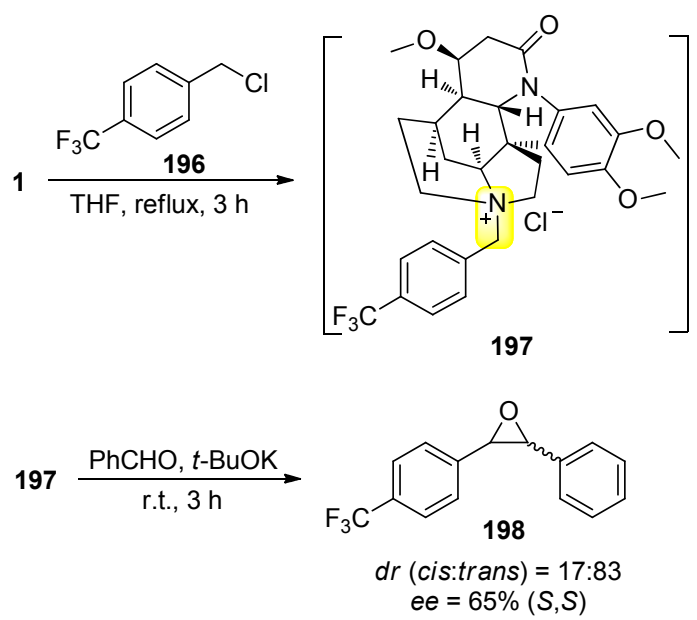

图式 59 环氧化合物 198 的合成

Scheme 59 Synthesis of epoxy compound 198

2017 年, Nicolaou 课题组 ${ }^{[82]}$ 使用 Oh 课题组的方法 得到了马钱子碱双差基化的衍生物 68. 随后，利用叔胺 氮的亲核性，与对三氟甲基苠溴(199)反应，以 $92 \%$ 的收 率得到了相应的铵盐 200 (Scheme 60).
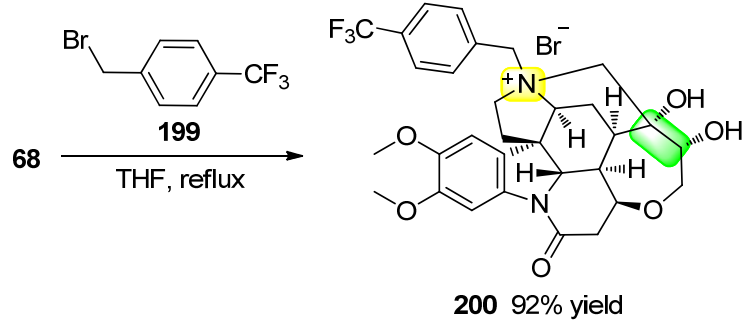

图式 60 铵盐 200 的合成

Scheme 60 Synthesis of ammonium salt 200

铵盐 200 可以作为手性相转移催化剂, 催化蒽酮 201 的不对称烯丙基化反应(Scheme 61). 在该反应中, 蒽酩 201 的 10 号位被去质子化得到相应的碳负离子. 由 于手性铵盐 200 的氮原子带有正电荷, 可以与碳负离子 作用，依靠手性铵盐 200 的手性实现了在 10 号位置的不 对称烯丙基化. 通过高效液相色谱测得该反应的选择性 较低, $d r(10 S: 10 R)$ 值仅为 $56 ： 44$. 然而, 通过奎宁类 的相转移催化剂可以实现很好的手性诱导效果 ${ }^{[82]}$. 


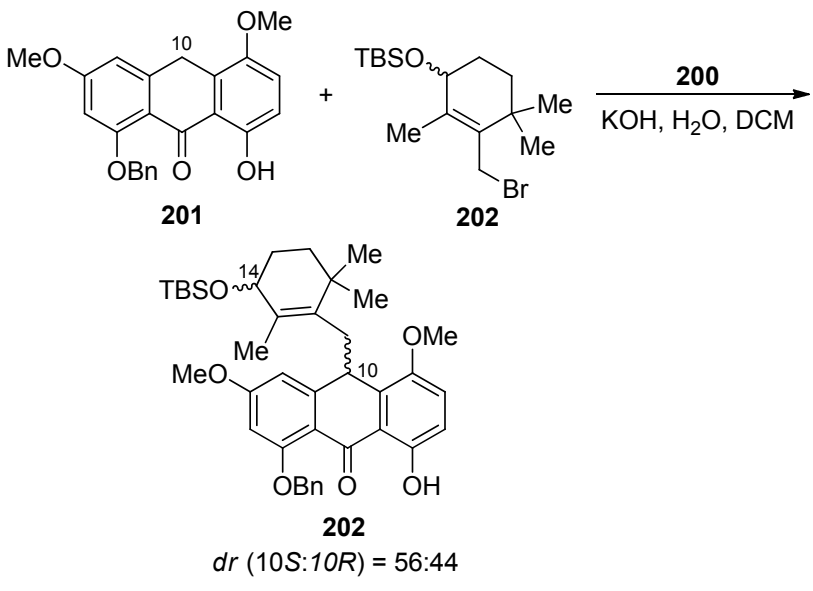

图式 61 萝酮 201 的不对称官能团化反应

Scheme 61 Asymmetric functionalization of anthrone 201

\section{4 总结和展望}

本文综述了关于马钱子碱结构修饰和手性应用的 最新进展. 马钱子碱具有芳基、醚、酰胺、叔胺、 $\mathrm{C}=\mathrm{C}$ 双键等结构单元和复杂的并环、螺环、桥环立体结构, 对 其进行选择性结构修饰具有很高的难度, 目前已有多种 方法实现了在其特定位点的选择性反应. 结构修饰后的 产物具有独特的生物活性, 可作为手性配体或助剂应用 到不对称合成中. 手性应用方面, 马钱子碱作为手性拆 分试剂, 广泛应用于外消旋羧酸、磷(膦)酸、酚、醇和 药物的拆分. 此外, 马钱子碱本身也可作为不对称合成 中的手性配体、手性催化剂或手性助剂.

目前针对马钱子碱的研究仍有不完善之处. 第一, 大部分工作者只对马钱子碱进行了结构修饰, 并没有进 一步测试马钱子碱衍生物的生物活性. 第二, 大部分马 钱子碱衍生物还有待进一步发掘其合成应用价值, 如肜 衍生物 22 本身具有羟基, 有作为新型手性配体的潜质. 第三, 作为手性拆分试剂拆分药物时, 由于马钱子碱毒 性较高, 一般不会优先采用. 从马钱子碱衍生物中篮选 易制备且低毒性的拆分试剂是值得研究的方向.

对马钱子碱的研究有很大的实际应用意义, 已证实 马钱子碱及其衍生物具有一定的潜在医用价值. 得益于 专业研究人员的贡献, 马钱子碱结构修饰的产物数目得 到了一定的扩展. 然而, 碍于不同专业人员之间的交流 限制, 鲜有对其药理、毒理测试的报道. 因此将马钱子 碱衍生物应用于实际药物, 依然任重而道远, 未来还需 要来自不同学科的研究人员的通力合作.

\section{References}

[1] (a) Hai, P.; Wang, C.; Luo, G. Chin. J. Pharm. 2016, 47, 1394 (in Chinese).

(海平, 王慧春, 骆桂法, 中国医药工业杂志, 2016, 47, 1394.)

(b) Zhang, J.-J.; Yang, Y.-J.; Qi, L.-P.; Dong, Y.-Y.; Zhang, J.; Li, R.-K.; Liu, Y.-M. Rheum. Arthritis 2017, 6, 38 (in Chinese).
(张景姣, 杨艳娇, 祁利平, 董艳艳, 张健, 李瑞柯, 刘雅敏, 风 湿病与关节炎, 2017, 6, 38.)

(c) Duan, C.-X.; Guo, C.-J. Chin. J. Pharm. Anal. 2018, 38, 331 (in Chinese).

(段存贤，郭承军，药物分析杂志, 2018, 38, 331.)

(d) Zhou, S.; Zhou, H.; Chen, Y.; Meng, F. Acta Chin. Med. 2018, 33, 1302 (in Chinese).

(周淑娟, 周红敏，陈岩岩，孟菲，中医学报， 2018，33，1302.)

(e) Liu, M.; Cui, X.; Shi, H.; Wang, X.; Chen, Z.; Niu, A.; Gao, R.; Cao, X. China Pharm. 2019, 30, 2980 (in Chinese).

(刘满军, 崔小敏, 石会丽, 王晓萍, 陈志永, 牛安琦, 高蓉, 曹 小平, 中国药房, 2019, 30, 2980.)

[2] (a) Wu, X.-J.; Ma, F.-S.; Yu, Y. Lishizhen Med. Mater. Med. Res. 2016, 27, 2145 (in Chinese).

(吴小娟，马凤森，喻炎，时珍国医国药，2016, 27, 2145.)

(b) Yan, J.; Lin, J.-T.; Liu, Z.-Q.; Zhen, X.-Y. Chin. J. Pharm. Anal. 2020, 40, 132 (in Chinese).

(间静，林佳娣，刘志强，甄晓宇，药物分析杂志， 2020, 40, 132.)

(c) Dong, Z.; Yang, Z.; Xu, J. Univ. Chem. 2020, DOI: 10.3866/PKU.DXHX202005056 (in Chinese).

(董子阳, 杨占会, 许家喜, 大学化学, 2020, DOI: 10.3866/PKU. DXHX202005056.)

[3] Wormley, T. Micro-chemistry of Poisons Including Their Physiological, Pathological, and Legal Relations: Adapted to the Use of the Medical Jurist, Physician, and General Chemist, Wood, W., New York, 1869.

[4] Buckingham, J. Bitter Nemesis: The Intimate History of Strychnine, CRC Press, Boca Raton, USA, 2007, p. 225.

[5] Frédérich, M.; Choi, Y. H.; Verpoorte, R. Planta Med. 2003, 69, 1169.

[6] Malone, M. H.; St. John-Allan, K. M.; Bejar, E. J. Ethnopharmacol. 1992, 35, 295.

[7] (a) Ren, J.; Zhang, X.; Chu, Z. J. Liaoning Univ. Tradit. Chin. Med. 2016, 18, 221 (in Chinese).

(任佳佳, 张学顺, 褚志杰, 辽宁中医药大学学报, 2016, 18, 221.) (b) Zhang, M.; Wang, C.; Wen, Q.; Fang, P.-F. Chin. J. Clin. Pharmacol. Ther. 2017, 33, 2282 (in Chinese).

(张敏, 王超, 温菁, 方平飞, 中国临床药理学杂志, 2017, 33, 2282.)

[8] Shiba, T. Kagaku Sosetsu 1976, 14, 129.

[9] (a) Yin, W.; Wang, T.-S.; Yin, F.-Z.; Cai, B.-C. J. Ethnopharmacol. 2003, 88, 205.

(b) Li, G.; Zhang, C.; Li, Z. Famous Doctor 2018, 147 (in Chinese). (李国璋, 张超, 李泽, 名医, 2018, 147.)

(c) Li, Y.-F.; Ren, W. Chin. J. Pain Med. 2019, 25, 94 (in Chinese).

(李永丰, 任维, 中国疼痛医学杂志, 2019, 25, 94.)

(d) Li, Y.; Zhou, J. Chin. J. Mod. Appl. Pharm. 2019, 36, 2805 (in Chinese).

(李阳杰，周敬，中国现代应用药学, 2019, 36, 2805.)

(e) Shi, X.; Zhu, M.; Kang, Y.; Yang, T.; Chen, X.; Zhang, Y. Phytomedicine 2018, 241.

(f) Suo, M.; Li, P.; Zhang, M.; Zhu, Y.; Xu, M.; Li, W. China Oncol. 2018, 28, 241 (in Chinese).

(索明珠, 李平, 张梅, 朱耀东, 徐梦冉, 李为雨, 中国癌症杂志, 2018, 28, 241.)

(g) Xu, M.; Li, P. Acta Univ. Med. Anhui 2020, 55, 195 (in Chinese).

(徐萌, 李平, 安徽医科大学学报, 2020, 55, 195.)

[10] (a) Zhang, M.; Wang, C.; Cai, H.-L.; Wen, J.; Fang, P.-F. Curr. Med. Sci. 2019, 39, 890.

(b) Wu, X.; Ma, F.; Zheng, G. Pharmacol. Clin. Chin. Mater. Med. 2016, 32, 231 (in Chinese).

(吴小娟, 马凤森, 郑高利, 中药药理与临床, 2016, 32, 231.)

(c) Li, S.; Wang, X.-P. Int. J. Nanomed. 2017, 12, 5797.

(d) Qin, J.; Yang, L.; Sheng, X.; Sa, Z.; Huang, T.; Li, Q.; Gao, K.; Chen, Q.; Ma, J.; Shen, H. Oncol. Lett. 2018, 15, 6137.

(e) Ma, J.-B.; Qiu, H.-W.; Rui, Q.-H.; Liao, Y.-F.; Chen, Y.-M.; Xu, J.; Zhang, Y.; Zhu, Y.; Zhao, Y.-G. Anal. Chim. Acta 2018, 1020. 
[11] (a) Cai, B.-C.; Hattori, M.; Namba, T. Chem. Pharm. Bull. 1990, $38,1295$.

(b) Wang, D.-D.; Li, J.-S.; Cai, B.-C. Chin. Arch. Tradit. Chin. Med. 2009, 27, 435 (in Chinese).

(王丹丹, 李俊松, 蔡宝昌, 中华中医药学刊, 2009, 27, 435.)

(c) Chen, X.; Liu, L.; Zhu, W.; Chen, H.; Guan, Y. Jiangxi J. Tradit. Chin. Med. 2018, 49, 63 (in Chinese).

(陈谢谢, 刘丽丽, 朱卫丰, 陈丽华, 管咏梅, 江西中医药, 2018, 49, 63.)

[12] (a) Wu, F.; Li, A.; Guo, J. Pharm. Today 2017, 27, 355 (in Chinese). (吴菲, 李阿荣, 郭洁文, 今日药学, 2017, 27, 355.)

(b) Wang, M.; Qi, W. Acta Chin. Med. 2017, 32, 1236 (in Chinese).

(王明昭, 齐武强. 中医学报, 2017, 32, 1236.)

(c) Nie, Y.; Cao, L.; Xu, Z.; Xin, B. World Latest Medicine Information 2018, 18, 155 (in Chinese).

(聂彦彦，曹璐璐，徐志龙，辛波，世界最新医学信息文摘，2018， 18, 155.)

(d) Zhang, Y.-J.; Zhang, Z.-P.; Zhai, J.-L.; Tian, L. Guangzhou Chem. Ind. 2019, 47, 121 (in Chinese).

(张云静, 张自品, 张雪燕, 翟佳丽, 田蕾, 广州化工, 2019，47, 121.)

[13] Liu, S.; Li, H.; Jiang, M.; Li, P. J. Instrum. Anal. 1998, 17, 5 (in Chinese).

(刘守清, 李慧玲, 蒋勉, 李培标, 分析测试学报, 1998, 17, 5.)

[14] (a) Blakemore, D. C.; Castro, L.; Churcher, I.; Rees, D. C.; Thomas, A. W.; Wilson, D. M.; Wood, A. Nat. Chem. 2018, 10, 383.

(b) Nicolaou, K. C.; Rigol, S. Angew. Chem. Int. Ed. 2019, 58, 11206.

[15] (a) Cernak, T.; Dykstra, K. D.; Tyagarajan, S.; Vachal, P.; Krska, S. W. Chem. Soc. Rev. 2017, 46, 1760

(b) White, M. C.; Zhao, J. J. Am. Chem. Soc. 2018, 140, 13988.

(c) Richardson, J.; Sharman, G.; Martínez-Olid, F.; Cañellas, S.; Gomez, J. E. React. Chem. Eng. 2020, 5, 779.

(d) Feng, K.; Quevedo, R. E.; Kohrt, J. T.; Oderinde, M. S.; Reilly, U.; White, M. C. Nature (London, U. K.) 2020, 580, 621.

[16] (a) Mohsen, A. M. Y.; Mandour, Y. M.; Sarukhanyan, E.; Breitinger, U.; Villmann, C.; Banoub, M. M.; Breitinger, H.-G.; Dandekar, T.; Holzgrabe, U.; Sotriffer, C.; Jensen, A. A. Zlotos, D. P. J. Nat. Prod. 2016, 79, 2997.

(b) Svejstrup, T. D.; Ruffoni, A.; Julia, F.; Aubert, V. M.; Leonori, D. Angew. Chem. Int. Ed. 2017, 56, 14948.

(c) Wang, J.; Li, R.; Dong, Z.; Liu, P.; Dong, G. Nat. Chem. 2018, 10,866 .

(d) Ruffoni, A.; Juliá, F.; Svejstrup, T. D.; McMillan, A. J.; Douglas, J. J.; Leonori, D. Nat. Chem. 2019, 11, 426.

(e) Berger, F.; Plutschack, M. B.; Riegger, J.; Yu, W.; Speicher, S.; Ho, M.; Frank, N.; Ritter, T. Nature (London, U. K.) 2019, 567, 223.

(f) Nishii, Y.; Ikeda, M.; Hayashi, Y.; Kawauchi, S.; Miura, M. J. Am. Chem. Soc. 2020, 142, 1621.

[17] Meyer, A. U.; Slanina, T.; Yao, C.-J.; König, B. ACS Catal. 2016, 6, 369.

[18] (a) Borie, C.; Mondal, S.; Arif, T.; Briand, M.; Lingua, H.; Dumur, F.; Gigmes, D.; Stocker, P.; Barbarat, B.; Robert, V.; Nicoletti, C.; Olive, D.; Maresca, M.; Nechab, M. Eur. J. Med. Chem. 2018, 148, 306.

(b) Cierpiał, T.; Kiełbasiński, P.; Kwiatkowska, M.; Łyzwa, P.; Lubelska, K.; Kuran, D.; Dąbrowska, A.; Kruszewska, H.; Mielczarek, L.; Chilmonczyk, Z.; Wiktorska, K. Bioorg. Chem. 2020, 94, 103454.

[19] (a) Otsuka, S.; Yorimitsu, H.; Osuka, A. Chem.-Eur. J 2015, 21, 14703.

(b) Chen, W.; Hooper, T. N.; Ng, J.; White, A. J. P.; Crimmin, M. R. Angew. Chem. Int. Ed. 2017, 56, 12687.

(c) Shigeno, M.; Okawa, T.; Imamatsu, M.; Nozawa-kumada, K.; Kondo, Y. Chem.-Eur. J. 2019, 25, 10294.

[20] (a) Figueroa-Valverde, L.; Diaz-Cedillo, F.; Garcia-Cervera, E.; Pool-Gomez, E.; Camacho-Luis, A.; Rosas-Nexticapan, M.;
Lopez-Ramos, M.; May-Gil, I.; Sarao-Alvarez, A.; Naal-Dzib, C. Asian J. Chem. 2013, 25, 6783 .

(b) Figueroa-Valverde, L.; Diaz-Cedillo, F.; Rosas-Nexticapa, M.; Garcia-Cervera, E.; Pool-Gomez, E.; Lopez-Ramos, M.; HauHeredia, L.; Sarabia-Alcocer, B. J. Chem. 2014 757953/1-757953/10.

(c) Figueroa-Valverde, L.; Diaz-Cedillo, F.; Garcia-Cervera, E.; Gomez, E. P.; Rosas-Nexticapa, M.; Lopez-Ramos, M. Asian J. Chem. 2014, 26, 4959.

[21] Fuentes de Arriba, A. L.; Lenci, E.; Sonawane, M.; Formery, O.; Dixon, D. J. Angew. Chem. Int. Ed. 2017, 56, 3655.

[22] (a) Fleming, F. F.; Yao, L.; Ravikumar, P. C.; Funk, L.; Shook, B. C. J. Med. Chem. 2010, 53, 7902 .

(b) Klein, B. A.; Robertson, I. M.; Reiz, B.; Kampourakis, T.; Li, L.; Sykes, B. D. ACS Med. Chem. Lett. 2019, 10, 1007.

(c) Lameira, J.; Bonatto, V.; Cianni, L.; dos Reis Rocho, F.; Leitão, A.; Montanari, C. A. Phys. Chem. Chem. Phys. 2019, 21, 24723.

[23] (a) Qi, L.; Hu, K.; Yu, S.; Zhu, J.; Cheng, T.; Wang, X.; Chen, J.; Wu, H. Org. Lett. 2017, 19, 218.

(b) Seo, B.; Kim, Y. G.; Lee, P. H. Org. Lett. 2016, 18, 5050.

(c) Kouznetsov, V. V.; Galvis, C. E. P. Tetrahedron 2018, 74, 773.

[24] Bender, T. A.; Payne, P. R.; Gagné, M. R. Nat. Chem. 2018, 10, 85.

[25] Zlotos, D. P. Buller, S. Holzgrabea, U. Mohr, K. Bioorg. Med. Chem. 2003, 11, 2627

[26] Cai, B.-C.; He, Y.-W.; Zhang, Y.-Q.; Wu, H. Chin. Pharm. J. 1994, 29, 169 (in Chinese). (蔡宝昌, 何亚维, 张永清, 吴皓, 中国药学杂志, 1994, 29, 169.)

[27] Arnone, A.; Metrangolo, P.; Novo, B.; Resnati, G. Tetrahedron 1998, 54, 7831.

[28] Jousseaume, B.; Chanson, E. Synthesis 1987, 155

[29] Chen, J.; Lü, P.; Zhou, X.-J. Chin. J. Org. Chem. 1987, 7, 459 (in Chinese). (陈坚, 吕平, 周洵钧, 有机化学, 1987, 7, 459.)

[30] Oh, K.; Knabe, W. E. Tetrahedron 2009, 65, 2966.

[31] Hansen, S. R.; Spangler, J. E.; Hansen, J. H.; Davies, H. M. L. Org. Lett. 2012, 14, 4626.

[32] He, J.; Hamann, L. G.; Davies, H. M. L.; Beckwith, R. E. J; Nat. Commun. 2015, 6, 5943.

[33] Brandhofer, T.; Gini, A.; Stockerl, S.; Piekarski, D. G.; Mancheño, O. G. J. Org. Chem. 2019, 84, 12992.

[34] Ross, S. P.; Hoye, T. R. Nat. Chem. 2017, 9, 523.

[35] Li, J.; Cisar, J. S.; Zhou, C.-Y.; Vera, B.; Williams, H.; Rodríguez, A. D.; Cravatt, B. F.; Romo, D. Nat. Chem. 2013, 5, 510.

[36] Fiori, K. W.; Du Bois, J. J. Am. Chem. Soc. 2007, 129, 562.

[37] Dong, Q.; Anderson, C. E.; Ciufolini, M. A. Tetrahedron Lett. 1995, 36,5681 .

[38] Maestre, L.; Dorel, R.; Pablo, O.; Escofet, I.; Sameera, W. M. C.; Álvarez, E.; Maseras, F.; Diaz-Requejo, M. M.; Echavarren, A. M.; Pérez, P. J. J. Am. Chem. Soc. 2017, 139, 2216.

[39] (a) Gharagozloo, P.; Lazareno, S.; Popham, A.; Birdsall, N. J. M. J. Med. Chem. 1999, 42, 438.

(b) Birdsall, N. J. M.; Farries, T.; Gharagozloo, P.; Kobayashi, S.; Lazareno, S.; Sugimoto, M. Mol. Pharmacol. 1999, 55, 778.

[40] (a) Král, V.; Pataridis, S.; Setnička, V.; Záruba, K.; Urbanová, M.; Volka, K. Tetrahedron 2005, 61, 5499.

(b) Kejík, Z.; Záruba, K.; Michalík, D.; Šebek, J.; Dian, J.; Pataridis, S.; Volka, K.; Král, V. Chem. Commun. (Cambridge, U. K.) 2006, 1533.

(c) Rezanka, P.; Záruba, K.; Král, V. Tetrahedron Lett. 2008, 49, 6448 .

(d) Záruba, K.; Králová, J.; Řezanka, P.; Poučková, P.; Veverková, L.; Král, V. Org. Biomol. Chem. 2010, 8, 3202.

[41] (a) Kim, H. Y.; Shi, H.-J.; Knabe, W. E.; Oh, K. Angew. Chem. Int. Ed. 2009, 48, 7420.

(b) Kim, H. Y.; Oh, K. Org. Lett. 2009, 11, 5682.

(c) Kim, H. Y.; Kim, S.; Oh, K. Angew. Chem. Int. Ed. 2010, 49 4476.

[42] Van Rheenen, V.; Kelly, R. C.; Cha, D. Y. Tetrahedron Lett. 1976 
1973.

[43] Karimov, R. R.; Sharma, A.; Hartwig, J. F. ACS Cent. Sci. 2016, 2, 715.

[44] (a) Eisenberger, P.; Gischig, S.; Togni, A. Chem.-Eur. J. 2006, 12, 2579.

(b) Parsons, A. T.; Buchwald, S. L. Angew. Chem. Int. Ed. 2011, 50, 9120 .

(c) Wang, X.; Ye, Y.; Zhang, S.; Feng, J.; Xu, Y.; Zhang, Y.; Wang, J. J. Am. Chem. Soc. 2011, 133, 16410.

(d) Mizuta, S.; Galicia-López, O.; Engle, K. M.; Verhoog, S.; Wheelhouse, K.; Rassias, G.; Gouverneur, V. Chem.-Eur. J. 2012, 18,8583 .

(e) Shimizu, R.; Egami, H.; Hamashima, Y.; Sodeoka, M. Angew. Chem. Int. Ed. 2012, 51, 4577.

(f) Wang, F.; Qi, X.; Liang, Z.; Chen, P.; Liu, G. Angew. Chem. Int. Ed. 2014, 53, 1881 .

[45] Lichosyt, D.; Zhang, Y.; Hurej, K.; Dydio, P. Nat. Catal. 2019, 2, 114.

[46] Wren, H.; Williams, H. J. Chem. Soc., Trans. 1916, 109, 572.

[47] Abderhalden, E.; Faust, W.; Haase, E. Z. Physiol. Chem. 1934, 228, 187.

[48] Toki, K. Bull. Chem. Soc. Jpn. 1958, 31, 333.

[49] (a) Toda, F.; Tanaka, K.; Ueda, H. Tetrahedron Lett. 1981, 22, 4669. (b) Toda, F.; Tanaka, K.; Mori, K. Chem. Lett. 1983, 827.

[50] Tanner, D. D.; Ruo, T. C. S.; Meintzer, C. P. J. Org. Chem. 1985, $50,2573$.

[51] Jaen, J. C. e-EROS Encycl. Reagents Org. Synth. 2001, doi. org/10. 1002/047084289X. rb334.

[52] (a) Hagishita, S.; Kuriyama, K.; Hayashi, M.; Nakano, Y.; Shingu, K.; Nakagawa, M. Bull. Chem. Soc. Jpn. 1971, 44, 496. (b) Warr, R. J.; Willis, A. C.; Wild, S. B. Inorg. Chem. 2008, 47, 9351.

[53] (a) Yoshida, S.; Kasai, M.; Kimura, T.; Akiba, T.; Takahashi, T.; Sakamoto, S. Org. Process Res. Dev. 2012, 16, 654.

(b) Moritomo, A.; Yamada, H.; Matsuzawa-Nomura, T.; Watanabe, T.; Itahana, H.; Oku, M.; Akuzawa, S.; Okada, M. Bioorg. Med. Chem. 2014, 22, 6026.

[54] (a) Holzwarth, R.; Bartsch, R.; Cherkaoui, Z.; Solladié, G. Chem.Eur. J. 2004, 10, 3931.

(b) Holzwarth, R.; Bartsch, R.; Cherkaoui, Z.; Solladié, G. Eur. J. Org. Chem. 2005, 3536.

(c) Tsunoda, Y.; Fukuta, K.; Imamura, T.; Sekiya, R.; Furuyama, T.; Kobayashi, N.; Haino, T. Angew. Chem. Int. Ed. 2014, 53, 7243.

[55] (a) Polavarapu, P. L.; Petrovic, A. G.; Vick, S. E.; Wulff, W. D.; Ren, H.; Ding, Z.; Staples, R. J. Org. Chem. 2009, 74, 5451.

(b) Yang, Z. Univ. Chem. 2020, 35, 185 (in Chinese). (杨占会, 大学化学, 2020,35, 185)

[56] Záruba, K.; Král, V. Tetrahedron: Asymmetry 2002, 13, 2567.

[57] (a) Tanaka, K.; Oda, S.; Nishihote, S.; Hirayama, D.; UrbanczykLipkowska, Z. Tetrahedron: Asymmetry 2009, 20, 2612. (b) Sundar, M. S.; Bedekar, A. V. RSC Adv. 2016, 6, 46258.

[58] Röehrich, T.; Abu Thaher, B.; Manicone, N.; Otto, H.-H. Monatsh. Chem. 2004, 135, 979 .
[59] Piwowarczyk, K.; Zawadzka, A.; Roszkowski, P.; Szawkalo, J.; Leniewski, A.; Maurin, J. K.; Kranz, D.; Czarnocki, Z. Tetrahedron: Asymmetry 2008, 19, 309.

[60] Doyle, M. P.; Morgan, J. P.; Fettinger, J. C.; Zavalij, P. Y.; Colyer, J. T.; Timmons, D. J.; Carducci, M. D. J. Org. Chem. 2005, 70, 5291.

[61] White, J. D.; Shaw, S. Org. Lett. 2011, 13, 2488.

[62] Carlier, P. R.; Zhang, Y. Org. Lett. 2007, 9, 1319.

[63] Mo, F.; Dong, G. Science (Washington, DC, U. S.) 2014, 345, 68.

[64] Chen, J.; Kilpatrick, B.; Oliver, A. G.; Wulff, J. E. J. Org. Chem. 2015, 80, 8979 .

[65] Chen, J.; Sun, X.; Oliver, A. G.; Wulff, J. E. Can. J. Chem. 2017, $95,234$.

[66] Zhu, J.; Yuan, Y.; Wang, S.; Yao, Z.-J. ACS Omega 2017, 2, 4665.

[67] Kenyon, J. Org. Synth. 1926, 6, 68.

[68] Hartmann, R. W.; Batzl, C.; Pongratz, T. M.; Mannschreck, A. J. Am. Chem. Soc. 1992, 35, 2210.

[69] (a) Poupaert, J. H.; Cavalier, R.; Claesen, M. H.; Dumont, P. A. J. Med. Chem. 1975, 18, 1268.

(b) Riedner, J.; Vogel, P. Tetrahedron: Asymmetry 2004, 15, 2657.

[70] Laursen, J. B.; Jorgensen, C. G.; Nielsen, J. Bioorg. Med. Chem. 2003, 11, 723 .

[71] Ashcroft, C. P.; Challenger, S.; Clifford, D.; Derrick, A. M.; Hajikarimian, Y.; Slucock, K.; Silk, T. V.; Thomson, N. M.; Williams, J. R. Org. Process Res. Dev. 2005, 9, 663.

[72] Dung, P. T.; Trung, T. Q.; Kim, K. H. Arch. Pharmacal Res. 2009, 32,1425 .

[73] Kuo, L. Y.; Glazier, S. K. Inorg. Chem. 2012, 51, 328.

[74] (a) Movassaghi, M.; Piizzi, G.; Siegel, D. S.; Piersanti, G. Angew. Chem. Int. Ed. 2006, 45, 5859.

(b) Hazin, K.; Patrick, B. O.; Gates, D. P. Inorg. Chem. 2019, 58, 188 .

[75] (a) Matsumoto, K.; Uchida, T. Chem. Lett. 1981, 1673.

(b) Ikemoto, T.; Nagata, T.; Yamano, M.; Ito, T.; Mizuno, Y.; Tomimatsu, K. Tetrahedron Lett. 2004, 45, 7757.

[76] Kano, T.; Ohyabu, Y.; Saito, S.; Yamamoto, H. J. Am. Chem. Soc. 2002, 124, 5365.

[77] (a) Marckwald, W. Ber. 1904, 37, 349.

(b) Toussaint, O.; Capdevielle, P.; Maumy, M. Tetrahedron Lett. 1987, 28,539 .

[78] (a) Drabowicz, J.; Legędź, S.; Mikołajczyk, M. J. Chem. Soc., Chem. Commun. 1985, 23, 1670.

(b) Drabowicz, J.; Legędź, S.; Mikołajczyk, M. Tetrahedron 1988, $44,5243$.

[79] Spek, A. L.; Voorbergen, P.; Schat, G.; Blomberg. C.; Bickelhaupt, F. J. Organomet. Chem. 1974, 77, 147.

[80] (a) Kolesińska, B.; Kamiński, Z. J. Org. Lett. 2009, 11, 765. (b) Kolesińska, B.; Kasperowicz, K.; Sochacki, M.; Mazur, A.; Jankowski, S.; Kamiński, Z. J. Tetrahedron Lett. 2010, 51, 20.

[81] Kinoshita, H.; Ihoriya, A.; Ju-Ichi, M.; Kimachi, T. Synlett 2010, 2330.

[82] Nicolaou, K. C.; Liu, G.; Beabout, K.; McCurry, M. D.; Shamoo, Y. J. Am. Chem. Soc. 2017, 139, 3736. 